\title{
Photoactive boron-nitrogen-carbon hybrids: from azo-borazines to polymeric materials
}

Hamid Oubaha,,${ }^{\dagger} \S$ Nicola Demitri, ${ }^{\circ}$ Joëlle Rault-Berthelot,,${ }^{\ddagger}$ Philippe Dubois, ${ }^{\S}$ Olivier Coulembier,,${ }^{*}$ and Davide

$$
\text { Bonifazi†,\#,* }
$$

†Department of Chemistry, University of Namur, Rue de Bruxelles 61, 5000 Namur, Belgium; § Laboratory of Polymeric and Composite Materials (LPCM), Center of Innovation and Research in Materials and Polymers (CIRMAP), University of Mons, Place du Parc 23, 7000 Mons, Belgium; ${ }^{\circ}$ Elettra-Sincrotrone Trieste, S.S. $14 \mathrm{Km}$ 163.5 in Area Science Park, 34149 Basovizza, Trieste, Italy; Univ. Rennes, CNRS, ISCR-6226, F-35000 Rennes, France; "School of Chemistry, Cardiff University, Main Building, Park Place, Cardiff, CF10 3AT, United Kingdom.

KEYWORDS: azobenzene, borazine, molecular switches, trans/cis isomerization, cross-coupling, polymers, polythiophene, solvatochromism.

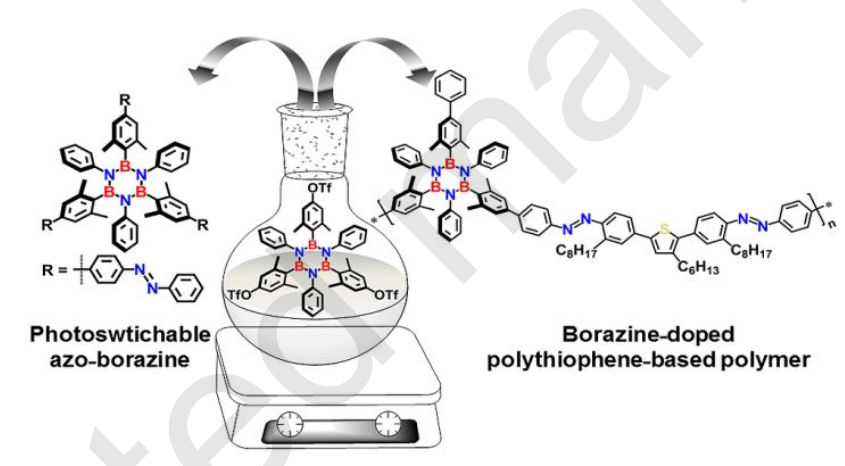

\begin{abstract}
In this paper, we describe the synthetic routes for preparing a novel switchable BNC-based chromophore, composed of a borazine core peripherally functionalized with azobenzene moieties. Capitalizing on the Pd-catalyzed Suzuki cross-coupling reaction between a tris-triflate borazine and an organoboron azobenzene derivative, a photoswticheable azo-borazine derivative was successfully prepared. The molecule showed reversible $E / Z$ photoisomerization upon irradiation at the maximum of the intense $\pi-\pi^{*}$ absorption feature (360 nm). X-Ray crystallographic investigations revealed a non-planar orientation of the three azobenzene moieties and the trans configuration of the $-\mathrm{N}=\mathrm{N}$ - bonds. Building on the synthetic versatility of the borazine-azobenzene derivative, we used this photoactive scaffold to engineer soluble BN-doped polythiophene polymers. Photophysical characterization performed in solvents of different polarity, suggested that the polymer undergoes intramolecular charge-transfer (ICT).
\end{abstract}




\section{INTRODUCTION}

Stimuli-responsive molecules and materials capable of undergoing reversible structural changes are of great interest for future technology. ${ }^{1}$ A typical example is the $E / Z$ photoisomerization of azobenzenes, which is characterized by an irradiation-induced $Z \rightarrow E$ isomerization between the thermodynamically favored, stretched $E$-isomer and its $Z$-isomer. The photoisomerization is accompanied by a dramatic change in electronic structure, geometric shape, and polarity, resulting into the spatiotemporal control of the conformational and overall structural properties of molecular systems. ${ }^{2}$ Notable applications include their integration into architectures expressing functional properties in materials science, ${ }^{3}$ biology ${ }^{4}$ and molecular recognition. ${ }^{1 c, 5}$

The replacement of $\mathrm{C}=\mathrm{C}$ units by more polarized $\mathrm{BN}$ couples is a versatile functionalization strategy to tailor the optoelectronic characteristics of organic $\pi$-systems without significant structural alteration of the nanostructure. ${ }^{6}$ The BN/CC isosterism concept goes back to the seminal discovery of the borazine $\left(\mathrm{H}_{3} \mathrm{~B}_{3} \mathrm{~N}_{3} \mathrm{H}_{3}\right)$ by Stock and Pohland in $1926 .^{7}$ The borazine core is commonly referred to as the "inorganic benzene", owing to its iso-electronic and iso-structural relationships with benzene. ${ }^{7}$ Accordingly, borazine and its derivatives are valuable scaffolds to be inserted as doping units in graphitic-based carbon materials to tailor their optoelectronic characteristics ${ }^{8}$ and self-assembly properties on surfaces..$^{9}{ }^{23}$ Important examples include dendritic borazine-doped polyphenylenes, ${ }^{10}$ borazine-doped coronenes ${ }^{11}$ and borazino-based polymers. ${ }^{10}, 12$ Not only borazine-based materials, but also hybrid BNC-based architectures are attracting increasing consideration due to their thermal stability, mechanical robustness and tunable optoelectronic properties. ${ }^{13}$ In this respect, the incorporation of $\mathrm{BN}$ units into $\pi$-conjugated polymers is emerging as an evident route to broaden the scope of organic electronic materials. ${ }^{6 d, 13 b, 14}$ For their part, $\pi$-conjugated polymers have revolutionized the field of optoelectronics ${ }^{15}$ and are nowadays used to produce low-cost, large-area, and flexible electronic devices. ${ }^{16}$ In these materials, the tailoring of the LUMO/HOMO energy levels for a given application is of high importance. ${ }^{15 \mathrm{~d},}{ }^{17}$ Among the different strategies, the incorporation of heteroatomic units into the polymer structures such as boron and nitrogen atoms revealed to be a powerful strategy to prepare isostructural molecular ${ }^{6 c, 11,18}$ and polymeric materials ${ }^{6 \mathrm{~d},}$, $4 \mathrm{a}, 19$ bearing strong local dipole moments. ${ }^{14 a}, 14 b, 20$

Owing to the possibility of functionalizing the borazine core with different groups on the aryl substituents at the $N$ and $B$ atoms, ${ }^{6 e}, 7 \mathrm{~d}, 21$ and to the easy polymerization of thiophenes for producing low-cost and flexible electronic devices, we have envisaged to employ the borazine $\left(\mathrm{B}_{3} \mathrm{~N}_{3}\right)$ as the core skeleton and azobenzene as photo-responsive unit to engineer new photoswitchable molecular BNC hybrid materials (Fig. 1). Considering the conductive properties of poly(3-hexylthiophene) (P3HT), ${ }^{22}$ the 3-hexylthiophene scaffold was selected as monomeric unit to develop the polymer material. Also, we were not unmindful to exploit the side alkyl chains to enhance the solubility of the final material (Fig. 1b). 
a)

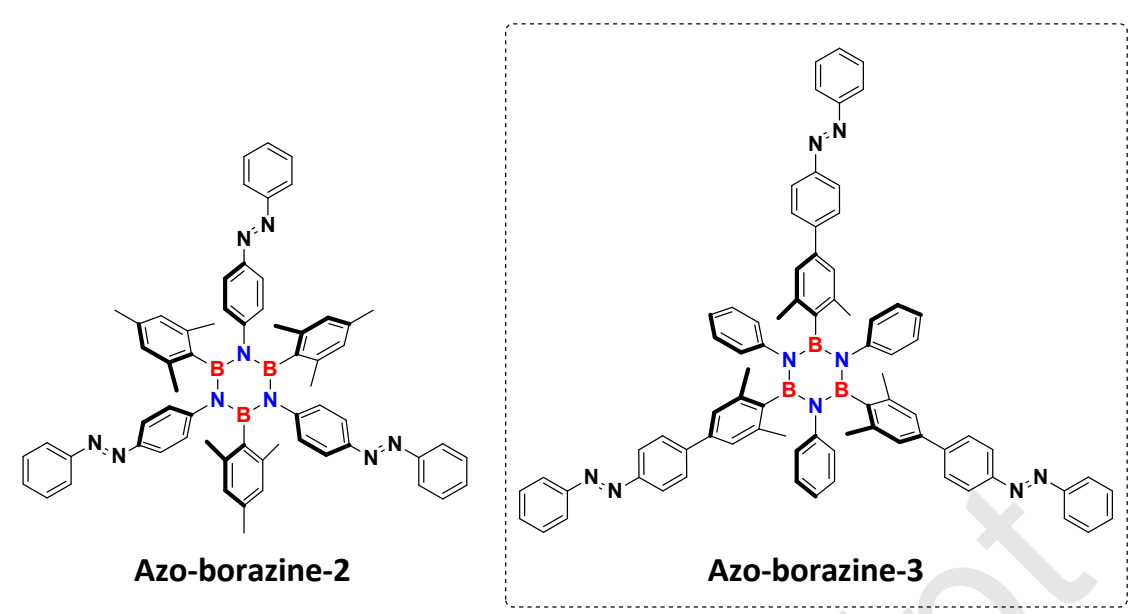

b)

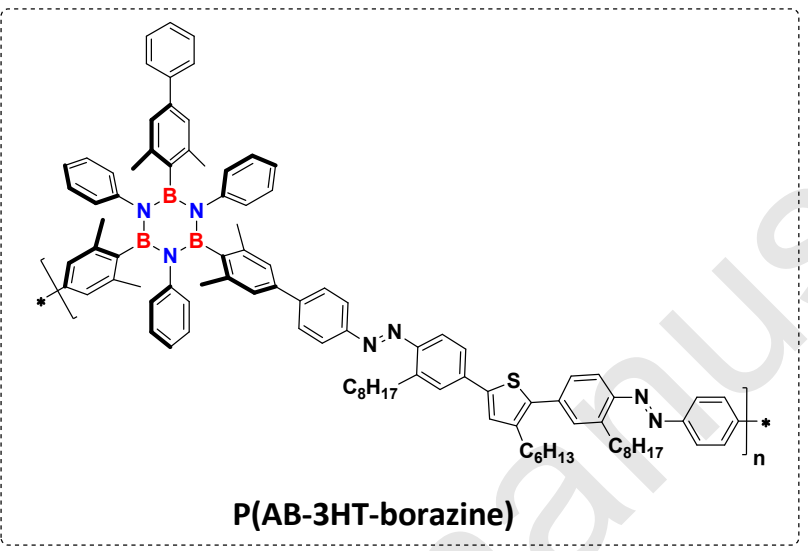

Figure 1. Molecular structures of the targeted borazine-based BNC molecules and hybrid polymers.

\section{RESULTS AND DISCUSSION}

Synthesis the azo-borazine core. Three classes of derivatives were targeted as photoactive BNC molecular scaffold: azo-borazine-1, azo-borazine-2, and azo-borazine-3 (Fig. 1a). Due to the chemical sensitivity of the $\mathrm{B}_{3} \mathrm{~N}_{3}$ core under the reaction conditions to form azobenzene moiety, azo-borazine-1 and azo-borazine-2 could not be prepared (see SI for the attempts). Thus, we decided to follow a convergent synthetic pathway, in which a precursor $\mathrm{B}_{3} \mathrm{~N}_{3}$ core is reacted with azobenzene moieties, avoiding the need to use strong oxidizing conditions to form the azo-functional group. It is following this approach, that we prepared azo-borazine-3 reacting a suitable aryl halide or related electrophile (i.e., ArOTf) with an organoboron derivative of a given azobenzene under the Suzuki cross-coupling reaction conditions (Scheme 1). Specifically, the tert-butyldimethylsilyl (TBDMS)-protected borazine derivative 3 was prepared following a modified protocol ${ }^{8,23}$ of that reported by Groszos and Stafiej ${ }^{24}$ and later by Yamaguchi. ${ }^{21}$ The synthesis started with the reaction of aniline $\mathbf{1}$ with $\mathrm{BCl}_{3}$ under refluxing conditions gave intermediate tri- $B$-chloro-tri- $N$-phenylborazine that, upon reaction with TBDMS-protected ArLi, could be transformed into TBDMS-protected borazine derivative 3 in $49 \%$ yield (reaction $\mathrm{a}-\mathrm{b}$ ). Removal of the TBDMS protecting group with TBAF and successive esterification with $\mathrm{Tf}_{2} \mathrm{O}$ in pyridine, led to key intermediate tris-triflate borazine 4 in 75\% yield (reactions c-d). ${ }^{10}$ White suitable crystals were obtained from evaporation of a solution containing either compound 3 (Fig. 2a) or compound 4 (Fig. 2 b) in $\mathrm{CHCl}_{3}$ belonging to the $P-1$ and $P 2_{1} / n$ space groups, respectively. As expected, the X-ray molecular structures show the quasi-orthogonal arrangement of the aryl moieties, which place the methyl substituents atop the $B$ atoms, sterically shielding the electrophilic $B$-centers. ${ }^{25}$ In parallel, the synthesis of the organoboron derivative of 
azobenzene $\mathbf{8}$ was performed through the Mills reaction, starting from commercially available nitrosobenzene 5 and 4-iodoaniline 6 followed by Miyaura borylation reaction (Scheme 1, reactions e-f). Final Suzuki cross-coupling reaction between borazine $\mathbf{4}$ and azobenzene-boronic ester $\mathbf{8}$ yielded desired azo-borazine-3 in $83 \%$ yield (Scheme 1, reaction $\mathrm{g}$ ).

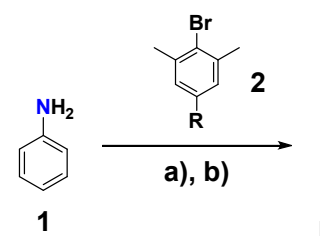

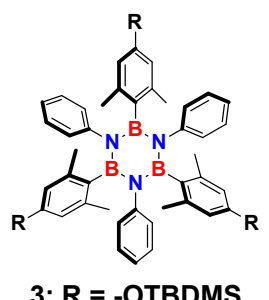

c), d)
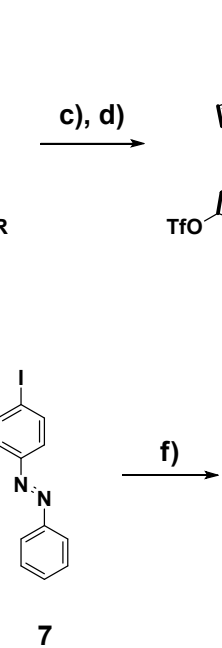<smiles></smiles>

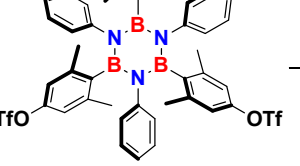

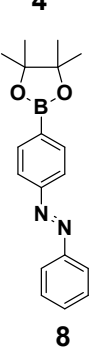

g)

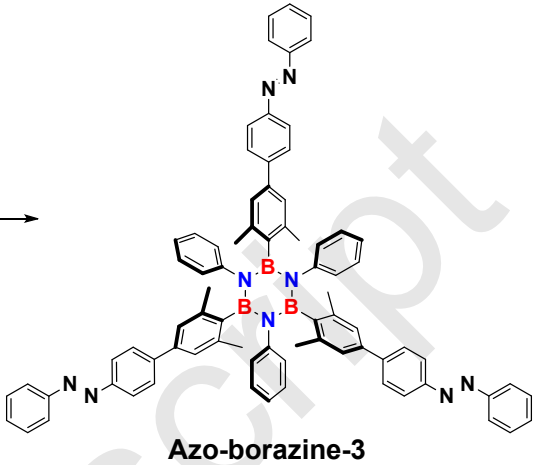

Scheme 1. Synthetic approach toward the preparation of azobenzene-borazine-based BNC hybrid materials. Reagents and conditions: (a) $\mathrm{BCl}_{3}$, toluene, reflux, $18 \mathrm{~h}$; (b) 2, tert-BuLi, THF, $-84{ }^{\circ} \mathrm{C}$ to r.t., 16 h, $49 \%$; (c) TBAF, THF, $0{ }^{\circ} \mathrm{C}, 2$ h; (d) $\mathrm{Tf}_{2} \mathrm{O}$, pyridine, r.t., 16 h, 75\%; (e) AcOH, r.t., 18 h, 81\%; (f) $\mathrm{B}_{2} \mathrm{Pin}_{2}, \mathrm{KOAc}$, [Pd(dppf) $\mathrm{Cl}_{2} \cdot \mathrm{CH}_{2} \mathrm{Cl}_{2}$ ], DMF, 80\%; (g) $\mathrm{K}_{2} \mathrm{CO}_{3}$, [Pd( $\left.\left.\mathrm{PPh}_{3}\right)_{4}\right]$, 1,4-dioxane: $\mathrm{H}_{2} \mathrm{O}(3: 1 \mathrm{v} / \mathrm{v}), 105{ }^{\circ} \mathrm{C}, 18 \mathrm{~h}, 83 \%$. TBAF: tetra-butylammonium fluoride. $\mathrm{Tf}_{2} \mathrm{O}$ : tri-fluoromethanesulfonic anhydride. $\mathrm{B}_{2} \mathrm{Pin}_{2}$ : 4,4,4',4',5,5,5',5'-Octamethyl-2,2'-bi-1,3,2-dioxaborolane.

$\left[\mathrm{Pd}(\mathrm{dppf}) \mathrm{Cl}_{2} \cdot \mathrm{CH}_{2} \mathrm{Cl}_{2}\right]$ :
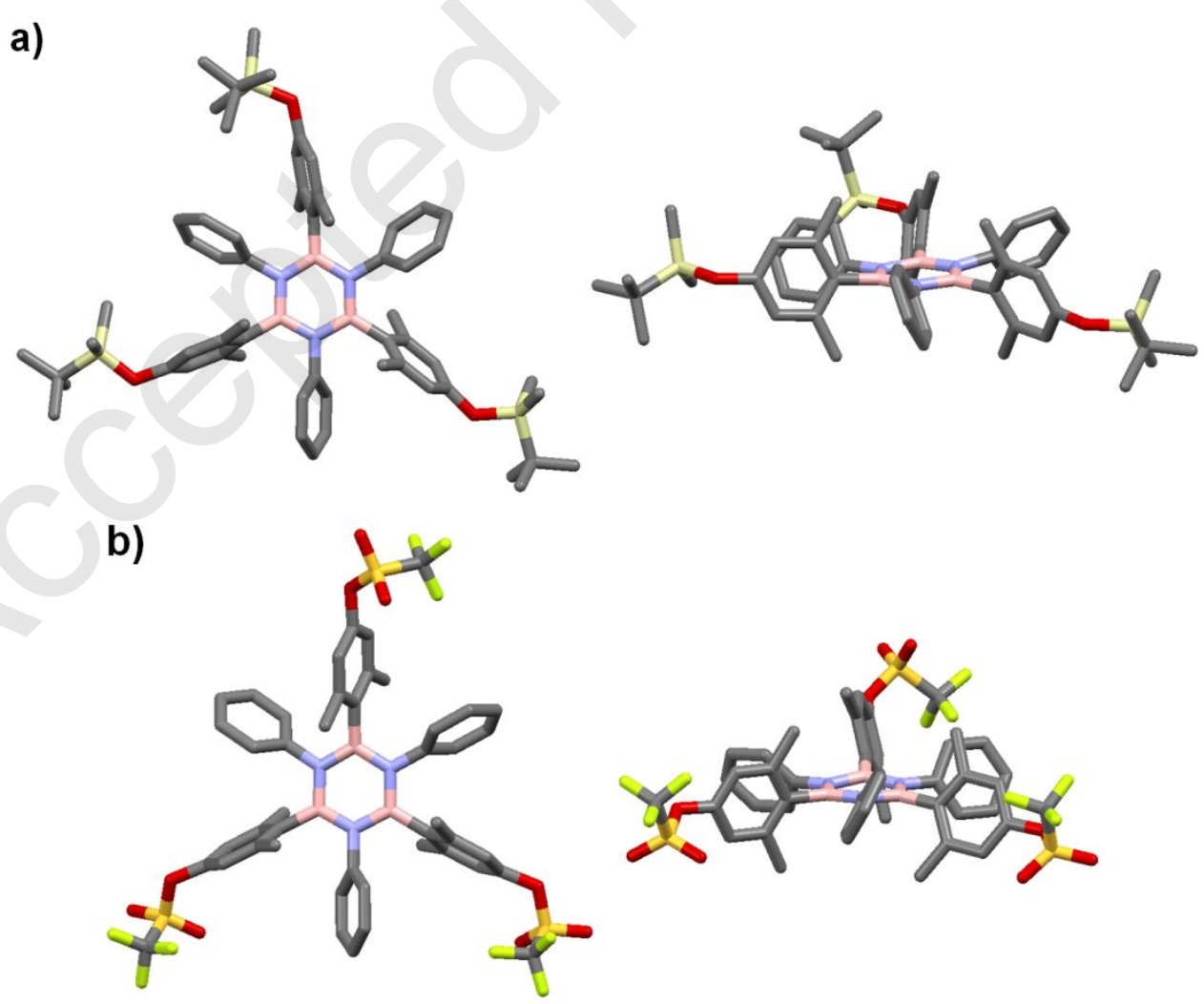

Figure 2. X-ray determined molecular structure of a) compound $\mathbf{3}$ and b) compound $\mathbf{4}$ (Atom colors: blue N, pink $\mathrm{B}$, red $\mathrm{O}$, yellow $\mathrm{Si}$, orange $\mathrm{S}$, light green $\mathrm{F}$, gray $\mathrm{C}$; hydrogen atoms are omitted for clarity). Space group: a) $P-1$ b) $P 2{ }_{1} / n$. 
Azo-borazine-3 derivative was characterized using NMR, IR, and MALDI-ToF spectrometry. At first, azo-borazine-3 was identified by MALDI-ToF through the detection of the peak corresponding to the molecular ion at $\mathrm{m} / \mathrm{z} 1162.6010\left([\mathrm{M}+\mathrm{H}]^{+}\right)$(calcd for $\mathrm{C}_{78} \mathrm{H}_{67} \mathrm{~B}_{3} \mathrm{~N}_{9}{ }^{+}$1162.5793). ${ }^{1} \mathrm{H} \mathrm{NMR}$ analysis further confirmed the chemical structure (Fig. 3) and the ${ }^{11}$ B NMR spectrum showed a broad peak at 36.0 ppm (inset Fig. 3), consistent with a boron atom substituted by two $N$-atoms and linked to one carbon atom. Finally, IR spectrum revealed an intense band at $1353 \mathrm{~cm}^{-1}$, characteristic of the B-N stretching in a borazine core. ${ }^{8}$
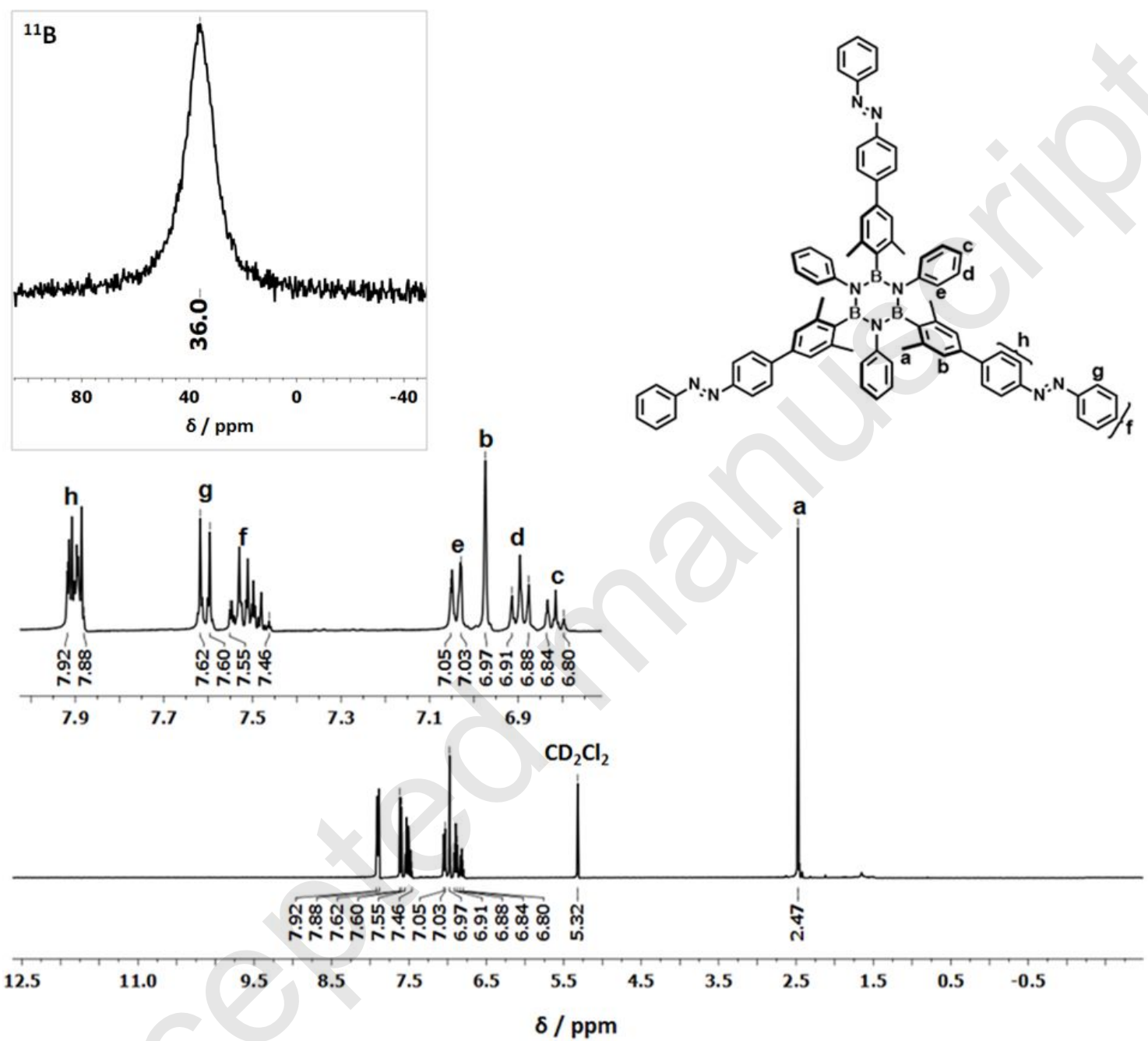

Figure 3. ${ }^{1} \mathrm{H}$ NMR spectrum of azo-borazine-3 $\left(\mathrm{CD}_{2} \mathrm{Cl}_{2}, 400 \mathrm{MHz}, 25^{\circ} \mathrm{C}\right)$. Inset: a zoom of the region $6.60-8.00$ ppm and ${ }^{11} \mathrm{~B}$ NMR spectrum $\left(\mathrm{CDCl}_{3}, 128 \mathrm{MHz}, 25^{\circ} \mathrm{C}\right)$.

Small needle-like orange crystals of azo-borazine-3 suitable for X-ray diffraction were grown by vapor diffusion of hexane to a solution of azo-borazine-3 in $\mathrm{CH}_{2} \mathrm{Cl}_{2}$. Similarly to borazine 4 , the X-ray molecular structure shows the quasi-orthogonal arrangement of the aryl moieties. The X-ray analysis confirms the trans configuration of the $-\mathrm{N}=\mathrm{N}$ - functional groups and reveals the non-planar arrangement of the three aryl rings at the solid state (Fig. 4a). A deviation from orthogonal arrangement of the aryl substituents and the borazine ring is clearly observed with inter-planar angles of $122.6^{\circ}$ between the borazine ring and phenyl groups, and of $108.9^{\circ}$ between both phenyl and xylyl groups. As previously observed in the literature, ${ }^{8,25}$ the intra-annular distance values between boron and nitrogen atoms are between 1.43 and $1.46 \AA$, with the internal angle of the borazine cycle between $122.7^{\circ}$ and $117.03^{\circ}$ (BNB and NBN, respectively). 

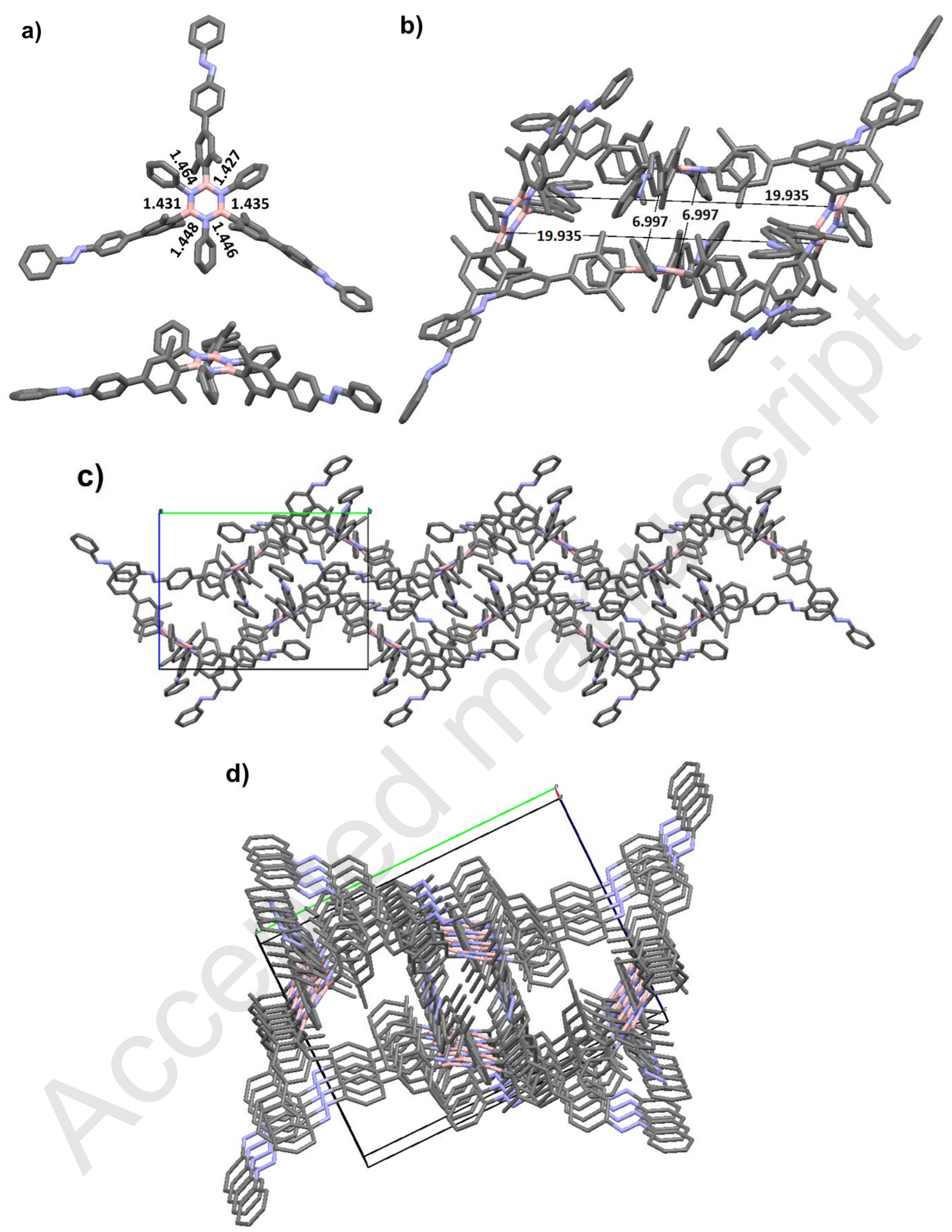

Figure 4. (a) Frontal (top) and side (bottom) views of the X-ray crystal structure of azo-borazine-3 (with the B-N distances in $\AA$ ), (b) packing diagram viewed along the $a$ axis and (c) Crystal packing, along the $a$ crystallographic direction, showing zigzag stacking shape of the molecules. (Atom colors: blue N, pink B, gray C; hydrogen atoms are omitted for clarity). Space group: $P 21 / c$. 
Notably, the azobenzene moieties in the crystal exist in a twisted shape with respect to the $B$-Aryl groups (Fig. 4a). Interestingly, the crystal packing four azo-borazine-3 molecules stack in parallelepiped-like fashion. The borazine cores constituting the four faces of the arrangement, with each $B$-center facing the $N$-center forming layers separated by a distance of 6.99 and $19.93 \AA$ (Fig. 4b). Each layer is formed by borazine molecules lying side by side on the same plane and separated by a distance of $20.22 \AA$ (Fig. 4c) and the adjacent layers are assembled in a zigzag-like stacking forming a 3D porous assembly (Fig. 4d).

Photo- and thermal-isomerizations of the azo-borazine-3. The photo-isomerization reaction between the $E$ - and Z-isomers of azo-borazine-3 was studied in toluene $\left(5 \cdot 10^{-6} \mathrm{M}\right)$ at r.t. (Fig. 5). The molecule exhibits two UV absorption bands at $360 \mathrm{~nm}$ and $450 \mathrm{~nm}$, which are attributed to $\pi-\pi^{*}$ (of the $E$-isomer) and $n$ - $\pi^{*}$ (of the $Z$-isomer) electronic transitions, respectively. ${ }^{2 b}, 26$ When irradiated at $360 \mathrm{~nm}$, remarkable changes are observed in the absorption spectra of the azo-borazine-3 (Fig. 5a), with an intense and fast increase of a new band centered at around $290 \mathrm{~nm}$ and a substantial increase of the intensity of the $n-\pi^{*}$ band at $450 \mathrm{~nm}$ (inset of Fig. 5a) with a concomitant disappearance of the $\pi-\pi^{*}$ absorption band. Neat isosbestic points are maintained throughout the photoirradiation experiments, showing the clean occurrence of the nearly quantitative $E \rightarrow Z$ isomerization after 3 min of irradiation, while no evolution in the UV-Vis absorption was observed even after 20 min of irradiation at $360 \mathrm{~nm}$. On the other hand, irradiation at $450 \mathrm{~nm}$ causes the $Z \rightarrow E$ isomerization, as observed by the simultaneous decrease and increase of the $n-\pi^{*}$ and $\pi-\pi^{*}$ absorption bands, respectively. The full restoring of the $E$-isomer was not observed even after $23 \mathrm{~min}$ of irradiation at $450 \mathrm{~nm}$ (Fig. 5b).
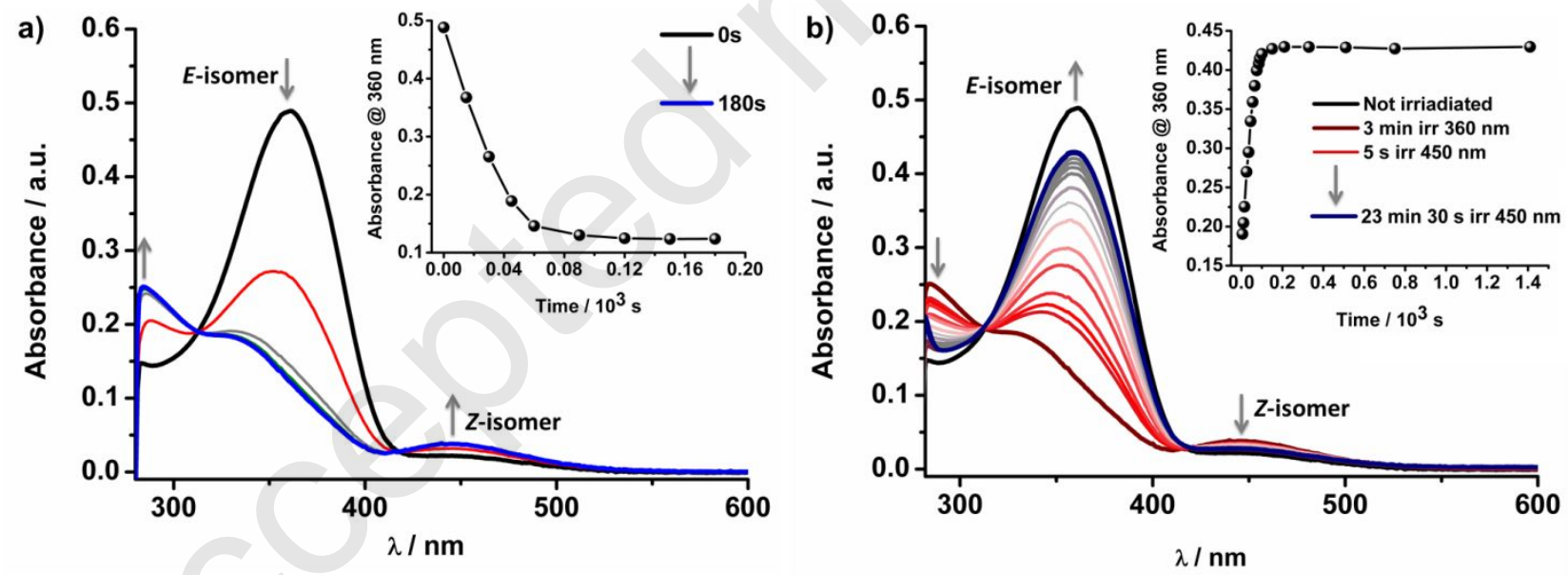

Figure 5. Reversible change in the absorption spectra of a $5 \cdot 10^{-6} \mathrm{M}$ solution of azo-borazine-3 in toluene under irradiation at (a) $360 \mathrm{~nm}$ and (b) $450 \mathrm{~nm}$ at r.t. $\left(23^{\circ} \mathrm{C}\right)$. Inset: UV absorption at $360 \mathrm{~nm}$ of azo-borazine-3 in toluene as a function of irradiation time.

Repetitive photo-induced switching cycles evidenced an excellent fatigue resistance and remarkable photostability of azo-borazine-3 (Fig. 6). As expected, the borazine core has little influence on the photochemical properties, with the azo-borazine-3 showing the typical E/Z switching behavior of standard azobenzenes. ${ }^{2 b,} 27 \mathrm{The} U \mathrm{~V}$ absorbing BN-core does not interfere with the excitation properties of the azobenzene moieties. The thermal $Z \rightarrow E$ isomerization (obtained after irradiation at $360 \mathrm{~nm}$ for $3 \mathrm{~min}$ ) was realized by measuring the absorbance of a $5 \cdot 10^{-6} \mathrm{M}$ solution of azo-borazine-3 in toluene at different temperatures (Fig. 7a). As shown in Figure 7, the 
thermal $Z \rightarrow E$ interconversion occurs very slowly, and the spectral profile of the $E$-isomer is fully recovered only upon heating at $100^{\circ} \mathrm{C}$.

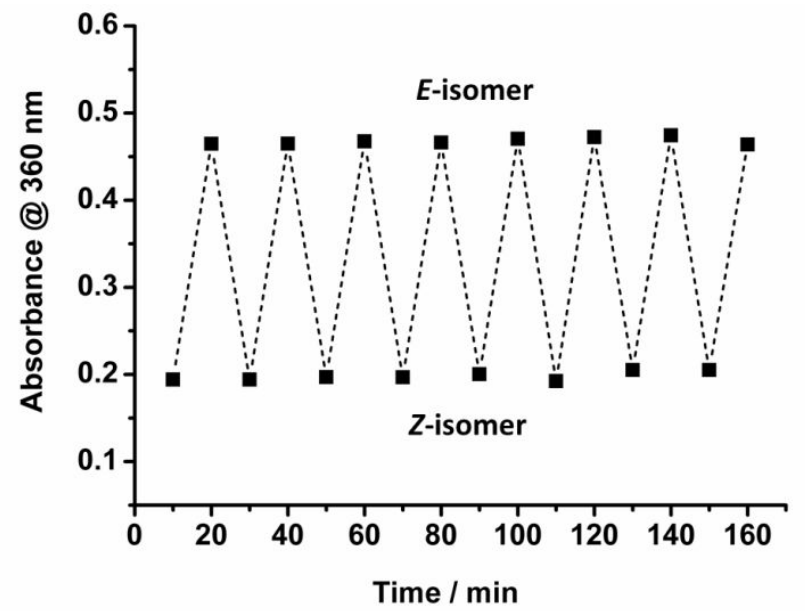

Figure 6. Repetitive photoinduced switching cycles of the azo-borazine-3 obtained by alternating irradiations at 360 and $450 \mathrm{~nm}\left(5 \cdot 10^{-6} \mathrm{M}\right.$ solution in toluene at $\left.23^{\circ} \mathrm{C}\right)$.
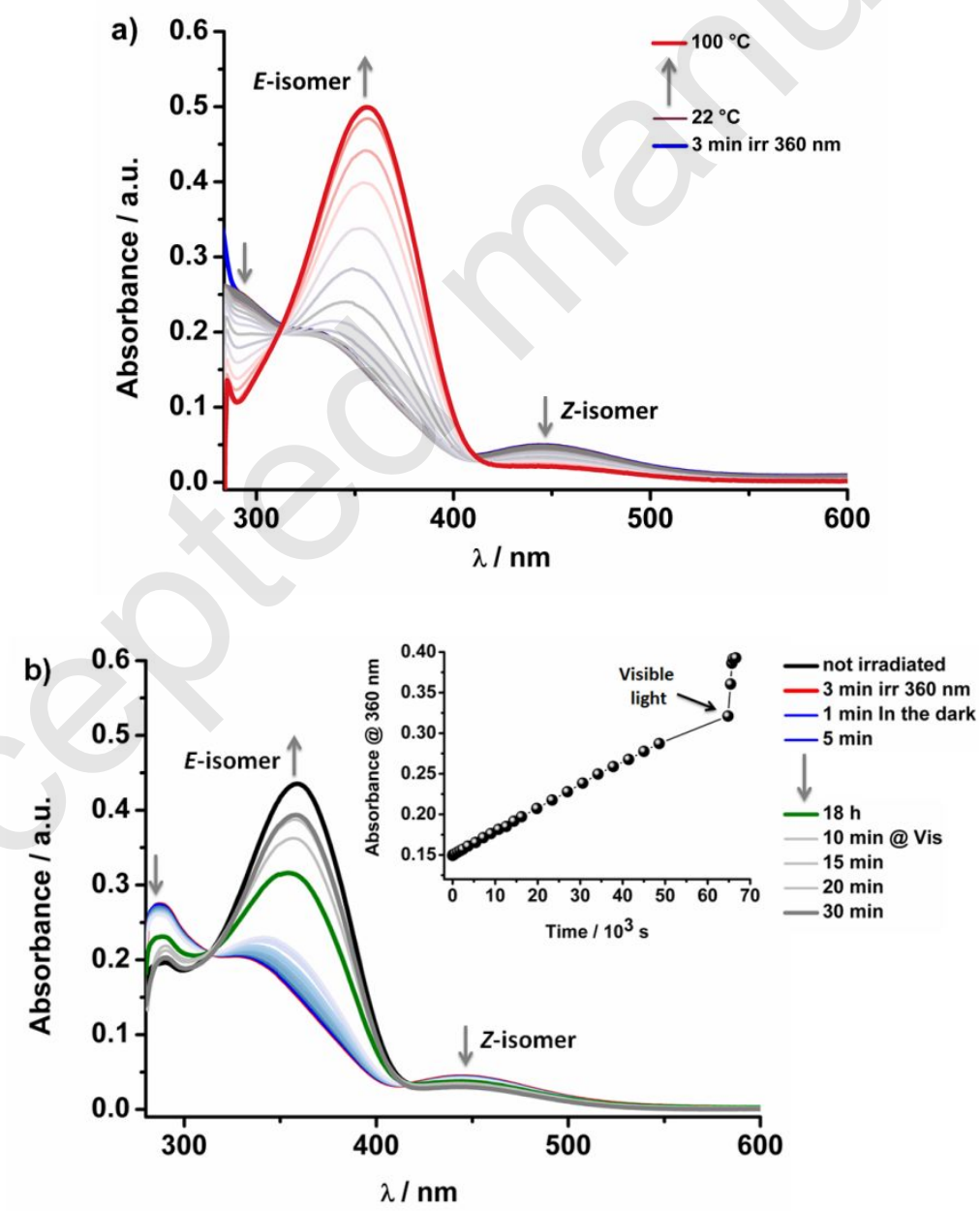

Figure 7. UV-Vis measurements of the thermal $Z \rightarrow E$ isomerization of azo-borazine-3 after sample irradiation at $360 \mathrm{~nm}\left(5 \cdot 10^{-6} \mathrm{M}\right.$ in toluene) (a) and at r.t. in the dark (b).

Self-assembly behavior of azo-borazine-3. To investigate the aggregation properties of azo-borazine-3, a THF/water mixture solvent was used to trigger the self-assembly into nanoparticles. Particles were formed by 
dissolving the azo-borazine-3 in THF containing various fractions $\left(f_{w}\right)$ of water at a concentration of $4.6 \cdot 10^{-6} \mathrm{M}$ under sonication at $40{ }^{\circ} \mathrm{C}$ for $15 \mathrm{~min}$. As shown in Figure 8a, in pure THF the absorption spectra of the azo-borazine- 3 consist of a strong absorption peak at $360 \mathrm{~nm}$ and a very weak band around $450 \mathrm{~nm}$ attributed to $\pi-\pi^{*}$ and $n-\pi^{*}$ electronic transitions of the azobenzene unit, respectively. Upon increasing the water fraction, the absorption spectra broadened and showed a hypochromic effect in intensity, suggesting the formation of aggregates. ${ }^{28}$ Similarly, emission measurements were recorded for the azo-borazine-3 under excitation at $360 \mathrm{~nm}$ (Fig. 8b). Azo-borazine-3 in THF exhibits an emission maximum at $406 \mathrm{~nm}$ with a fluorescence quantum yield $\left(\Phi_{f l}\right)$ of $0.82 \%$. An appreciable enhancement of the emission intensity was observed with increasing fractions of water, with the maximum being at $406 \mathrm{~nm}\left(\Phi_{f l}=3.28 \%, f_{w}=95 \%\right)$. In these compounds, intramolecular rotations play a crucial role to populate the non-radiative decay channels for the excited states and enhance their rates. ${ }^{29}$ The free intramolecular torsional motion in solution favours the non-radiative decays that are the responsible for the weak emission in THF. ${ }^{30}$ However, these torsional motions are hindered in the aggregated state. The enhancement of the emission in the aggregated state also suggested a suppression of the concentration quenching in the aggregated state by amplified intermolecular distances resulting from the partially distorted structure of the fluorogenic units. ${ }^{31}$
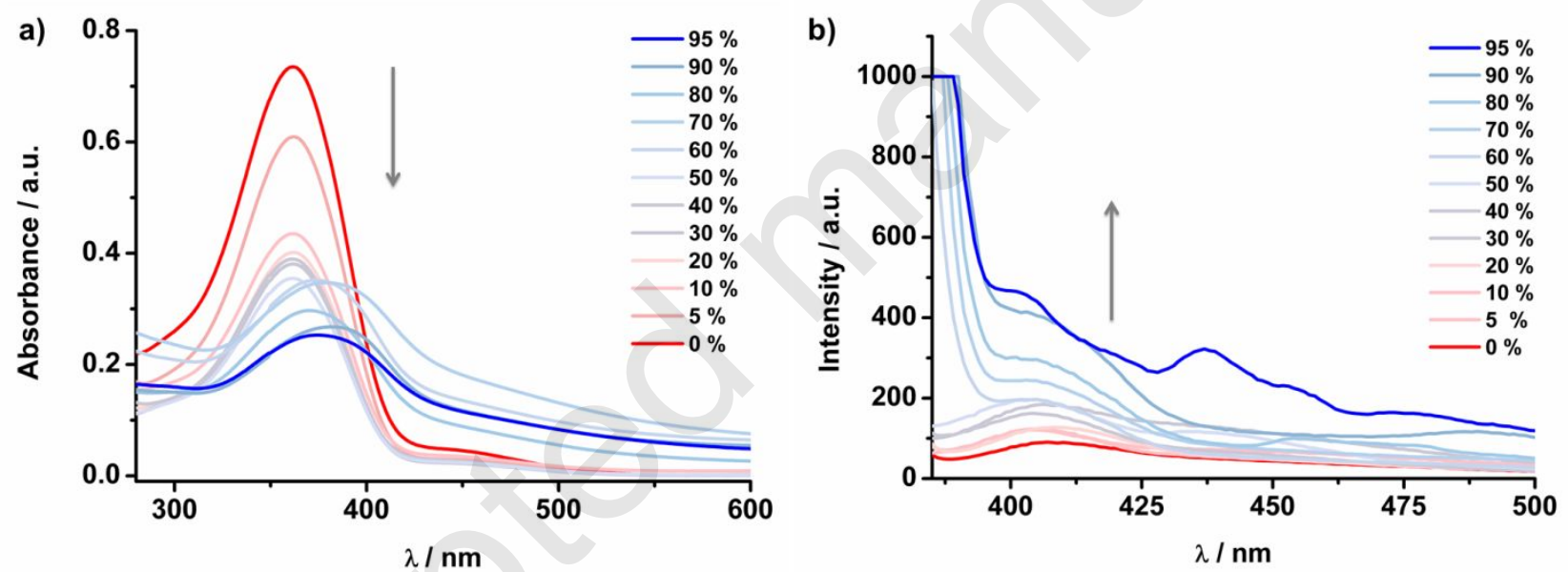

Figure 8. (a) Absorption and (b) fluorescence $\left(\lambda_{\text {excitation }}=360 \mathrm{~nm}\right)$ spectra of the azo-borazine-3 in THF with increasing water contents $\left(f_{w} \%\right)$ recorded at r.t. (The final concentration was $\left.4.6 \cdot 10^{-6} \mathrm{M}\right)$.

Then, we investigated the morphology of the as-formed aggregates using transmission electron microscope (TEM). Spherical aggregates with different diameters from $90 \mathrm{~nm}$ to $\sim 600 \mathrm{~nm}$ were obtained for samples containing azo-borazine-3 prepared in a THF/ $\mathrm{H}_{2} \mathrm{O}$ mixture $\left(f_{w}=95 \%\right)$ (Fig. 9a-d). Notably, some of the particles stick together to form large aggregates (Fig. 9e). Dynamic light scattering (DLS) measurements (Fig. 9f) performed on the same sample confirmed the presence of aggregates displaying hydrodynamic diameters ranging from $110 \pm 20 \mathrm{~nm}$ to $295 \pm 150 \mathrm{~nm}$, together with larger particles with hydrodynamic diameters of $4 \pm 1 \mu \mathrm{m}$. Since the formation of the nanoparticles involves stepwise addition of a poor solvophobic solvent $\left(\mathrm{H}_{2} \mathrm{O}\right)$ to a stable solution of the azo-borazine-3 in THF, the solubility of the molecule is gradually reduced upon addition of water, leading to the formation of aggregates. Larger nanoparticles are formed either through attractive $V d W$ or dipolar forces. As previously suggested by Ajayaghosh and co-workers for azobenzene-based nanodots, ${ }^{3 \mathrm{~g}}$ the growth of these aggregates could also be attributed to a light-driven "Ostwald ripening" -type mechanism. ${ }^{32}$ 


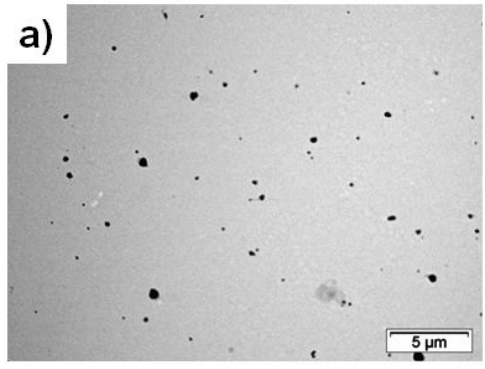

b)

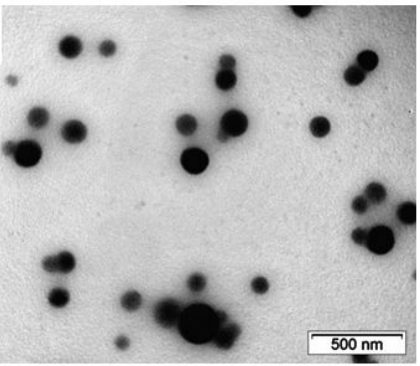

c)

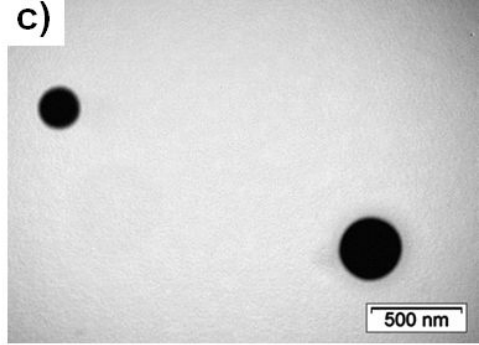

d)

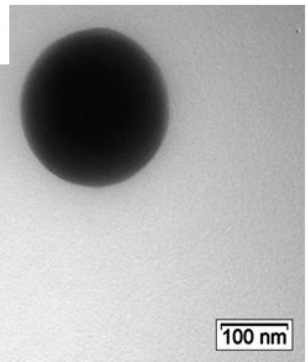

e)

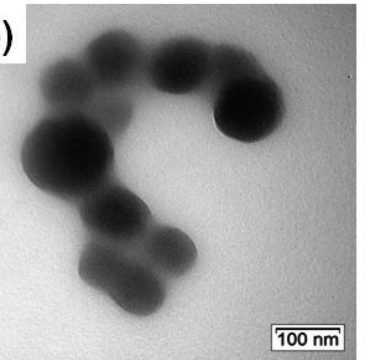

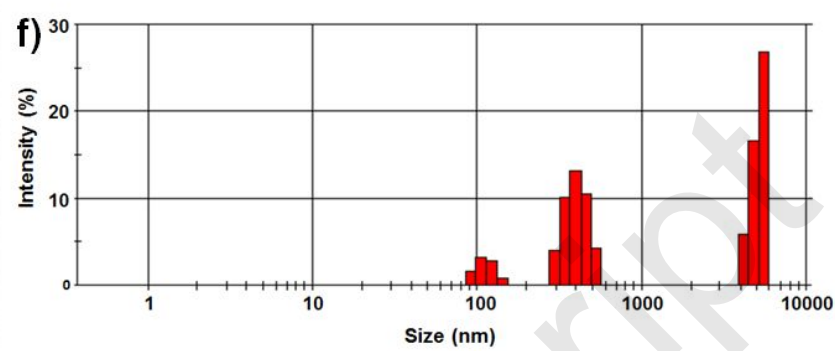

Figure 9. (a-e) TEM images of the azo-borazine-3 prepared from THF solution with $95 \%$ of water and (f) average size of the particles as measured by dynamic light scattering $\left(4.6 \cdot 10^{-6} \mathrm{M}, f_{w}=95 \%\right)$.

Synthesis of the borazine-doped polythiophene-based polymer. For the application of azo-borazine as building block in polymers main chain, the key issue is to introduce reactive groups on repetitive units. Therefore, we synthesized bis-triflate borazine derivative (bis-OTf-borazine) 9 starting from the tris-OTf-borazine 4 and azobenzene-functionalized thiophene derivative

$\left(\left(1 E, 1^{\prime} E\right)\right.$ -2,2'-((3-hexylthiophene-2,5-diyl)bis(2-octyl-4,1-phenylene))bis(1-(4-(4,4,5,5-tetramethyl-1,3,2-dioxaborolan-2-y 1)phenyl)diazene) (AB-3HT-(BPin) 2 ) 21 as monomers. Bis-OTf-borazine 9 was prepared in 30\% yield via Suzuki cross-coupling reaction between tris-OTf-borazine $\mathbf{4}$ and phenylboronic acid (Scheme 2, reaction a). In parallel, AB-3HT-(BPin) 21 monomer was prepared starting from 1 -bromo-2-nitrobenzene $\mathbf{1 0}$ and 1 -octyne through Sonogashira cross-coupling reaction leading to 1 -nitro-2-(oct-1-yn-1-yl)-benzene $\mathbf{1 1}$ in $90 \%$ yield (Scheme 2, reaction b). Compound 11 was quantitatively reduced using Pd-catalyzed hydrogenation yielding compound 12 (Scheme 2, reaction c). A regio-selective bromination of $\mathbf{1 2}$ by pyridinium hydrobromide perbromide gave 4-bromo-2-octylaniline 13 in 71\% yield (Scheme 2, reaction d). Miyaura borylation of compound 13 in 1,4-dioxane provided 2-octyl-4-(4,4,5,5-tetramethyl-1,3,2-dioxaborolan-2-yl)aniline $\mathbf{1 4}$ in 50\% yield (Scheme 2, reaction e). Compound 14 was then coupled to 3-hexyl-2,5-diiodothiophene 16, prepared in 90\% yield from 3-hexylthiophene 15 (Scheme 2, reaction f), via Suzuki cross-coupling reaction yielding (4,4'-(3-hexylthiophene-2,5-diyl)bis(2-octylaniline) 17 in 30\% yield (Scheme 2, reaction g). Compound 17 was reacted with 1-bromo-4-nitrosobenzene 19, prepared from 4-bromoaniline 18 (Scheme 2, reaction h), using Mills reaction conditions $^{33}$ giving access to (1E,1'E)-2,2'-((3-hexylthiophene-2,5-diyl)bis(2-octyl-4,1-phenylene))bis(1-(4-bromophenyl)diazene) $\mathrm{AB}-3 \mathrm{HT}-\mathrm{Br}_{2} \mathbf{2 0}$ in $45 \%$ yield (Scheme 2, reaction i). Miyaura borylation of compound $\mathbf{2 0}$ led to the desired monomer AB-3HT-(BPin) 22 in 65\% yield (Scheme 2, reaction j). Finally, the synthesis of the P(AB-3HT-borazine) polymer was carried out using a standard Suzuki cross-coupling polycondensation reaction (Scheme 2, reaction k). The molecular weight estimated by gel permeation chromatography (GPC) relative to polystyrene standard in THF $\left(+2 \% \mathrm{Et}_{3} \mathrm{~N}\right)$ at $30{ }^{\circ} \mathrm{C}$ was $13.2 \mathrm{kDa}$ with a dispersity $\left(\mathrm{Ð}_{\mathrm{M}}\right)$ of 1.92 and a degree of polymerization (DP) of 9 . 

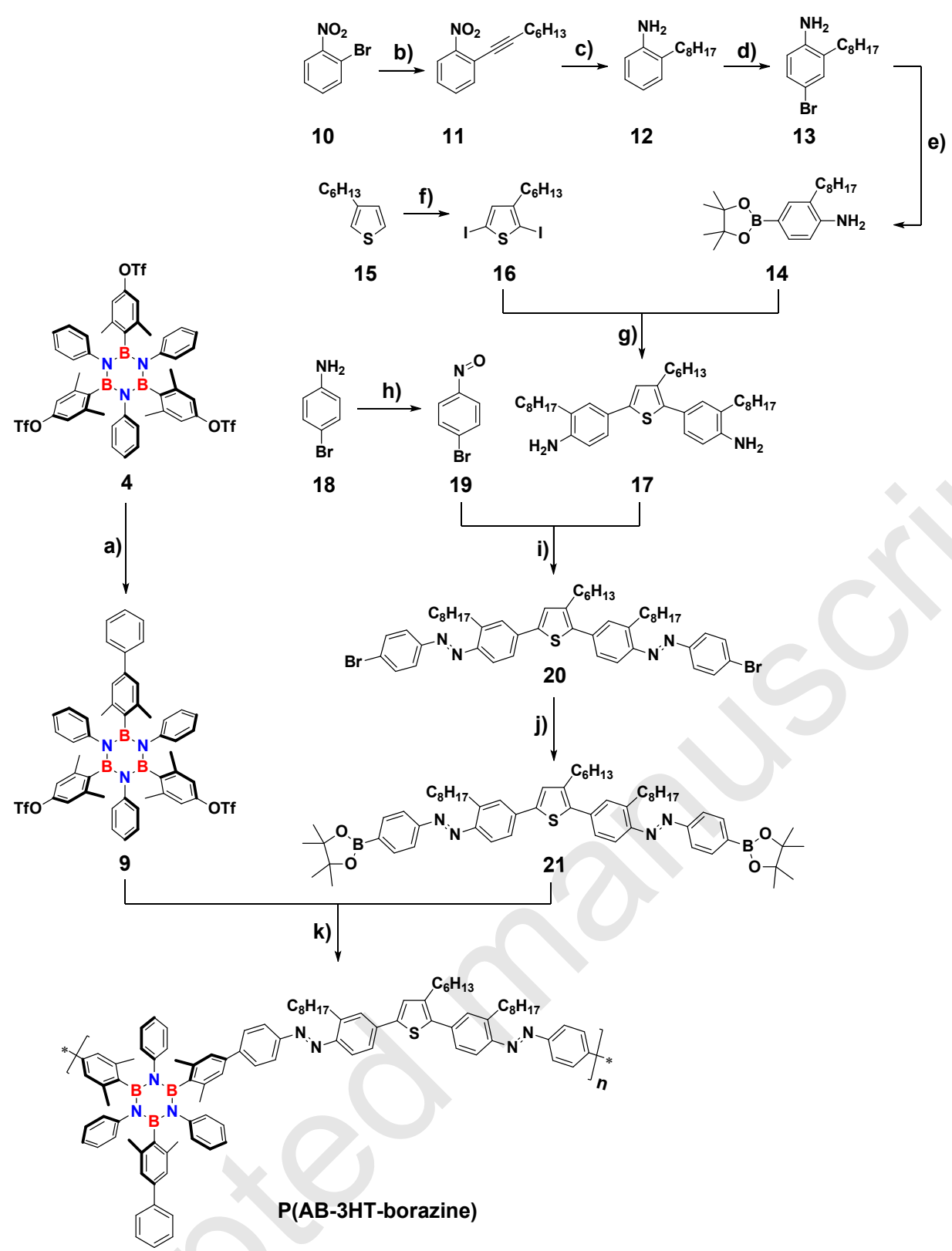

Scheme 2. Synthetic routes for preparing P(AB-3HT-borazine) polymer. Reagents and conditions: (a) Phenylboronic acid, [Pd( $\left.\left.\mathrm{PPh}_{3}\right)_{4}\right], \mathrm{K}_{2} \mathrm{CO}_{3}, 1$,4-dioxane:water $(3: 1 \mathrm{v} / \mathrm{v}), 100{ }^{\circ} \mathrm{C}, 8 \mathrm{~h}, 30 \%$; (b) 1-octyne, $\left[\mathrm{Pd}\left(\mathrm{PPh}_{3}\right)_{4}\right], \mathrm{CuBr}, \mathrm{Et}_{3} \mathrm{~N}, 90{ }^{\circ} \mathrm{C}, 15 \mathrm{~h} \mathrm{90 \%}$; (c) $\mathrm{H}_{2}$ (1 atm), $\mathrm{Pd} / \mathrm{C}(10$ wt.\%), EtOH, r.t., 6 h, $95 \%$; (d) pyridinium

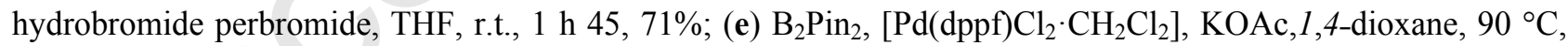
24 h, 50\%; (f) NIS, AcOH: $\mathrm{CHCl}_{3}\left(3: 4\right.$ v/v), r.t., 24 h, 90\%; (g) [ $\left.\mathrm{Pd}\left(\mathrm{PPh}_{3}\right)_{4}\right], \mathrm{K}_{2} \mathrm{CO}_{3}$, 1,4-dioxane: $\mathrm{H}_{2} \mathrm{O}(3: 1), 105$ ${ }^{\circ} \mathrm{C}, 24 \mathrm{~h}, 30 \%$; (h) oxone, $\mathrm{CH}_{2} \mathrm{Cl}_{2}: \mathrm{H}_{2} \mathrm{O}(1: 3 \mathrm{v} / \mathrm{v})$, r.t., $3 \mathrm{~h}$, quant.; (i) AcOH:EtOAc $(1: 1 \mathrm{v} / \mathrm{v}), 40{ }^{\circ} \mathrm{C}, 36 \mathrm{~h}, 45 \%$; (j) $\mathrm{B}_{2} \mathrm{Pin}_{2},\left[\mathrm{Pd}(\mathrm{dppf}) \mathrm{Cl}_{2} \cdot \mathrm{CH}_{2} \mathrm{Cl}_{2}\right]$, AcOK, 1,4-dioxane, $90{ }^{\circ} \mathrm{C}, 24 \mathrm{~h}, 65 \%$; (k) [Pd( $\left.\left.\mathrm{PPh}_{3}\right)_{4}\right], \mathrm{K}_{2} \mathrm{CO}_{3}$, toluene:water $(2: 0.2 \mathrm{v} / \mathrm{v}), 100^{\circ} \mathrm{C}, 48 \mathrm{~h}, 60 \%$. NIS: $N$-iodosuccinimide.

The polymer is soluble in common organic solvents such as $\mathrm{CH}_{2} \mathrm{Cl}_{2}$, chloroform, THF, toluene and insoluble in acetone, methanol and $n$-heptane. ${ }^{1} \mathrm{H}$ NMR spectrum of $\mathbf{P}\left(\mathbf{A B}-3 \mathrm{HT}\right.$-borazine) polymer in $\mathrm{CDCl}_{3}$ (Fig. 10) showed all characteristic peaks of its repeating units. The low-field shifting of the aromatic proton resonance of the (OTf)-aryl group of the borazine unit from $6.49 \mathrm{ppm}$ in the starting material (bis-OTf-borazine) to $6.92 \mathrm{ppm}$ in the polymer structure, suggests that the desired polymer has been formed. As revealed by thermogravimetric analysis (TGA) (Supporting Information, Fig. S25), P(AB-3HT-borazine) polymer exhibits good thermal stability with a mass loss of $5 \mathrm{wt} \%$ starting at $203{ }^{\circ} \mathrm{C}$, and a loss of about $30 \mathrm{wt} \%$ at $351^{\circ} \mathrm{C}$. On the other hands, DSC analysis performed from -25 to $200{ }^{\circ} \mathrm{C}$ showed a glass transition $\left(T_{\mathrm{g}}\right)$ at about $112{ }^{\circ} \mathrm{C}$. Moreover, no melting 
and crystallization peaks were detected, suggesting the amorphous nature of the polymer (Supporting Information, Fig. S26).

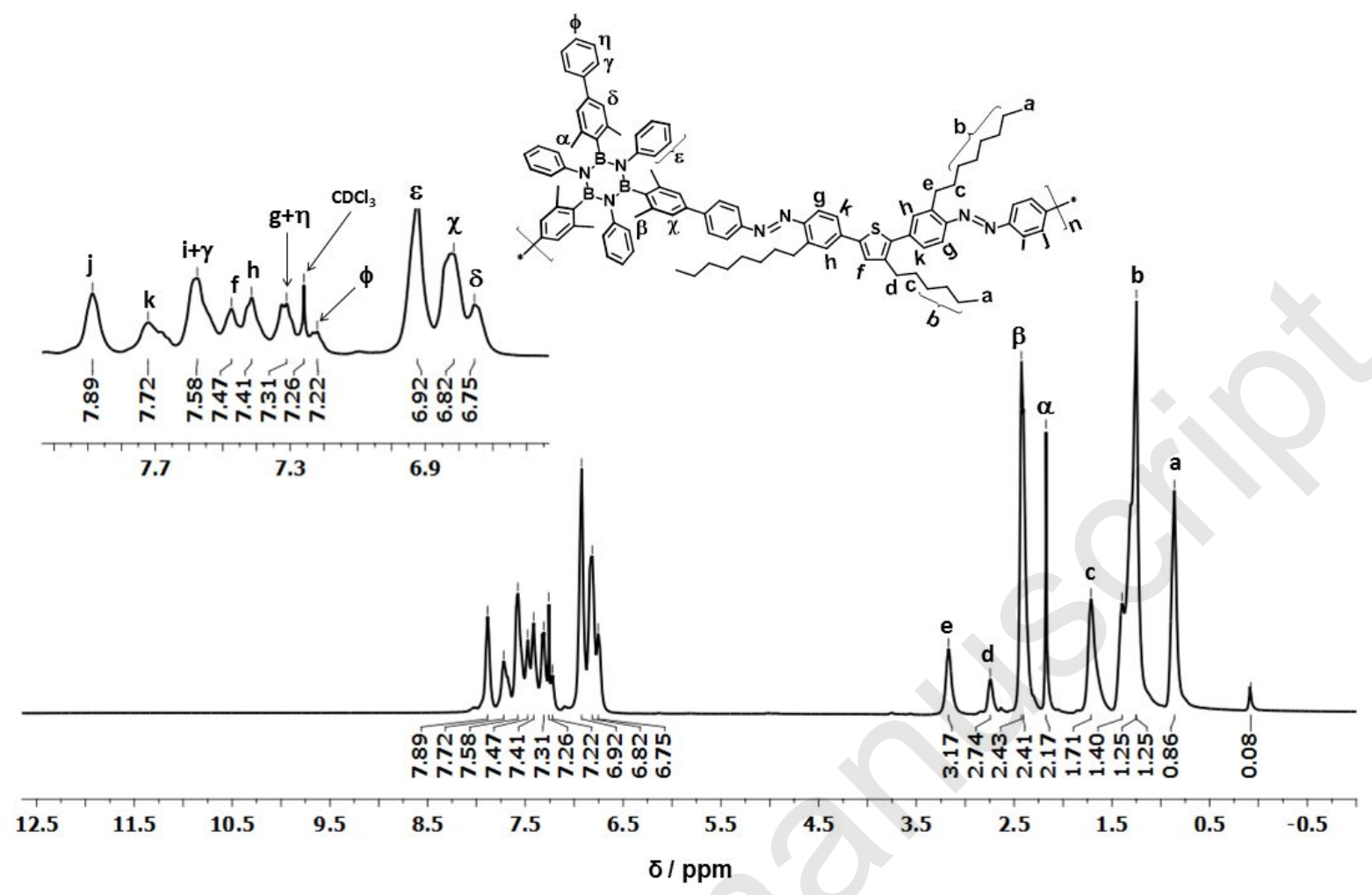

Figure 10. ${ }^{1} \mathrm{H}$ NMR spectrum of $\mathbf{P}\left(\mathbf{A B}-3 \mathrm{HT}-\right.$ borazine) polymer $\left(\mathrm{CDCl}_{3}, 500 \mathrm{MHz}, 25^{\circ} \mathrm{C}\right)$.

The absorption spectra of monomers bis-OTf-borazine 9, AB-3HT-(BPin) 21 as well as P(AB-3HT-borazine) polymer in solutions and in thin films are depicted in Figure 11.
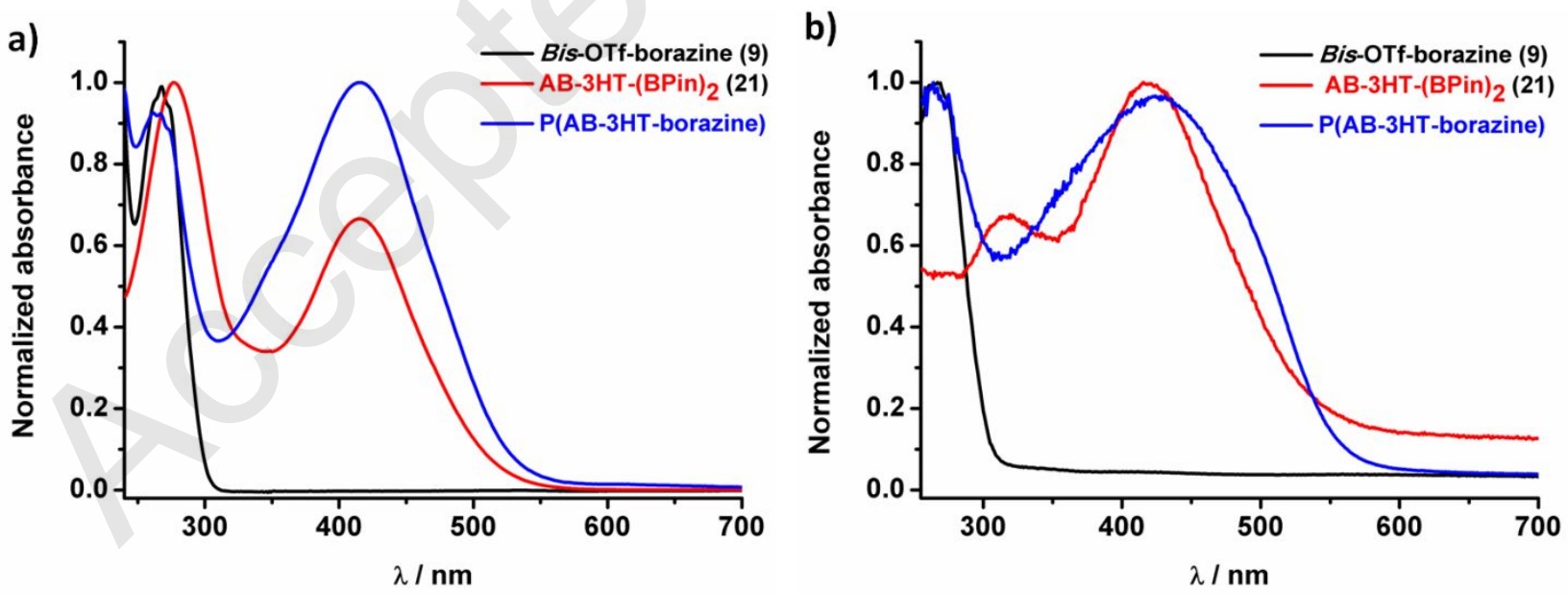

Figure 11. Normalized absorption spectra of monomers 9, 21 and $\mathbf{P}\left(\mathbf{A B}-3 \mathbf{H T}\right.$-borazine) polymer in $\mathrm{CHCl}_{3}$ solutions (a) and in thin films (b).

Absorption spectra of borazine unit either in solution or in film gave predominately one band at $268 \mathrm{~nm}$ and 266 $\mathrm{nm}$, respectively, corresponding to $\mathrm{S}_{0}-\mathrm{S}_{1}$ transition. Absorption spectra of thiophene derivative unit 29 in solution showed two absorption maxima at $276 \mathrm{~nm}$ and $416 \mathrm{~nm}$, corresponding to the $\mathrm{S}_{0}-\mathrm{S}_{2}$ and $\mathrm{S}_{0}-\mathrm{S}_{1}$ transitions, respectively. However, these bands are bathochromic shifted in the solid state. The P(AB-3HT-borazine) 
polymer showed dual absorption bands. The high-energy band at around $268 \mathrm{~nm}$ develops from overlapped maximum spectra of $\mathrm{S}_{0}-\mathrm{S}_{2}$ transitions of the borazine and the thiophene moieties, while, the low-energy band $(320-550 \mathrm{~nm})$ is ascribed to the absorption of the thiophene derivative unit. Furthermore, no other bands have been appeared at high wavelengths suggesting that no separate charge transfer occurred at the ground state. The band gap ( $\left.E_{\mathrm{g}}{ }^{\text {opt }}\right)$ of P(AB-3HT-borazine) polymer calculated from the absorption onsets (548 $\left.\mathrm{nm}\right)$ in the solid state is $2.27 \mathrm{eV}$, which is close to that of AB-3HT-(BPin $)_{2}$ derivative $(2.30 \mathrm{eV})$. Further, we have recorded emission spectra of the monomers $\left(\mathbf{9}\right.$ and 21) and the polymer $(\mathbf{P}(\mathbf{A B}-\mathbf{3 H T}$-borazine $))$ in $\mathrm{CHCl}_{3}\left(\lambda_{\mathrm{exc}}=268 \mathrm{~nm}\right.$, $276 \mathrm{~nm}$ and $416 \mathrm{~nm}$, Fig. 12). A well-resolved peak at $330 \mathrm{~nm}$ corresponding to the $\mathrm{S}_{1}-\mathrm{S}_{0}$ transition was observed when the borazine unit 9 is excited at $268 \mathrm{~nm}$, whereas thiophene monomer 21 predominately gave two emission maxima at $400 \mathrm{~nm}$ and $460 \mathrm{~nm}\left(\lambda_{\text {exc }}=276 \mathrm{~nm}\right)$, attributing to $S_{2}-S_{0}$ and $S_{1}-S_{0}$ electronic transitions, respectively. An emission maximum was obtained at $475 \mathrm{~nm}$ when excited at $416 \mathrm{~nm}$, corresponding to $\mathrm{S}_{1}-\mathrm{S}_{0}$ electronic transition. On the other hand, broad emission spectra were obtained when the polymer is excited at $268 \mathrm{~nm}$ and $276 \mathrm{~nm}$, with a maximum at $330 \mathrm{~nm}$. The broad nature of the spectra obtained for the polymer is attributed to the contribution of the borazine and the thiophene moieties. The excitation of polymer at $416 \mathrm{~nm}$ gave a weakly-emissive band between $560 \mathrm{~nm}$ and $550 \mathrm{~nm}$. In addition to the broad nature of the fluorescence spectra, the emission intensities are decreased compared to those of the reference borazine and thiophene derivatives alone, suggesting the occurrence of an intramolecular charge-transfer (ICT).

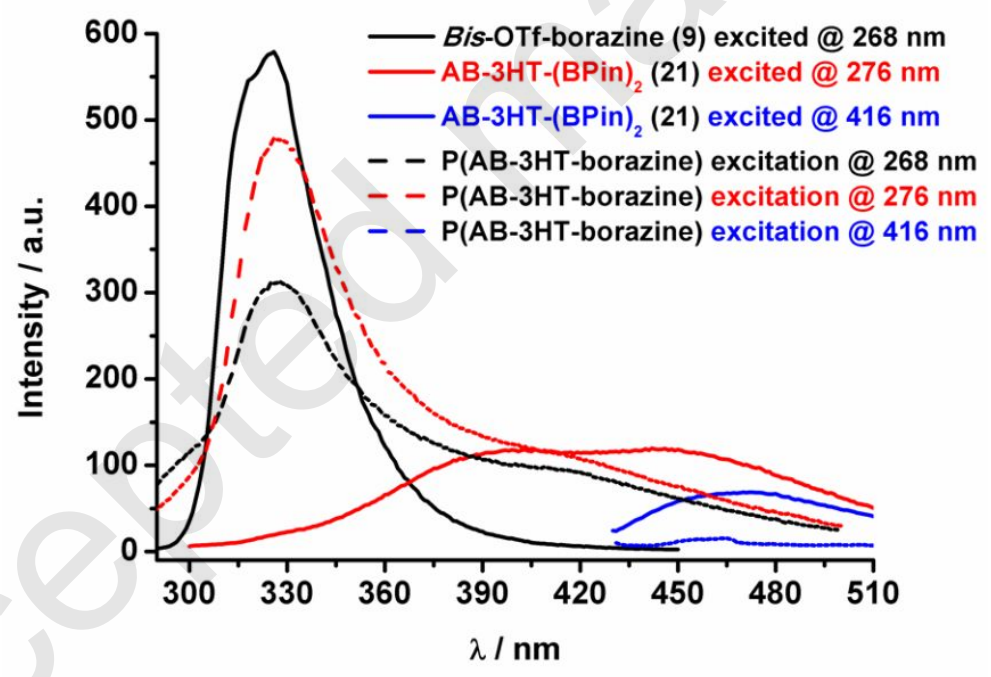

Figure 12. Emission spectra of bis-OTf-borazine 9, AB-3HT-(BPin) $2 \mathbf{2 1}$ and P(AB-3HT-borazine) polymer recorded at r.t. in $\mathrm{CHCl}_{3}\left(\lambda_{\text {exc }}=268 \mathrm{~nm}, 276 \mathrm{~nm}\right.$ and $\left.416 \mathrm{~nm}\right)$.

The photo-switching properties of the obtained P(AB-3HT-borazine) polymer was studied in $\mathrm{CHCl}_{3}(0.025 \mathrm{~g} / \mathrm{L})$ at r.t. When irradiated at the maximum absorption band $(440 \mathrm{~nm})$ no significant changes in the absorption band were noticed (Fig. 13), suggesting that the polymer does not undergo any photo-induced switching process. Considering that the band corresponding to the $\pi-\pi^{*}$ transition of the azo-group around 360 nm is veiled by the intense $\mathrm{S}_{0}-\mathrm{S}_{1}$ transition band of the thiophene derivative unit, one can hypothesize that the lack of a selective excitation of the azobenze moieties is the main reason for the unsuccessful polymer switching. Also, it cannot be excluded that an energy transfer from the excited state of the azobenzene to the oligothiophene could occur as well, quenching the photoisomerization reaction. 


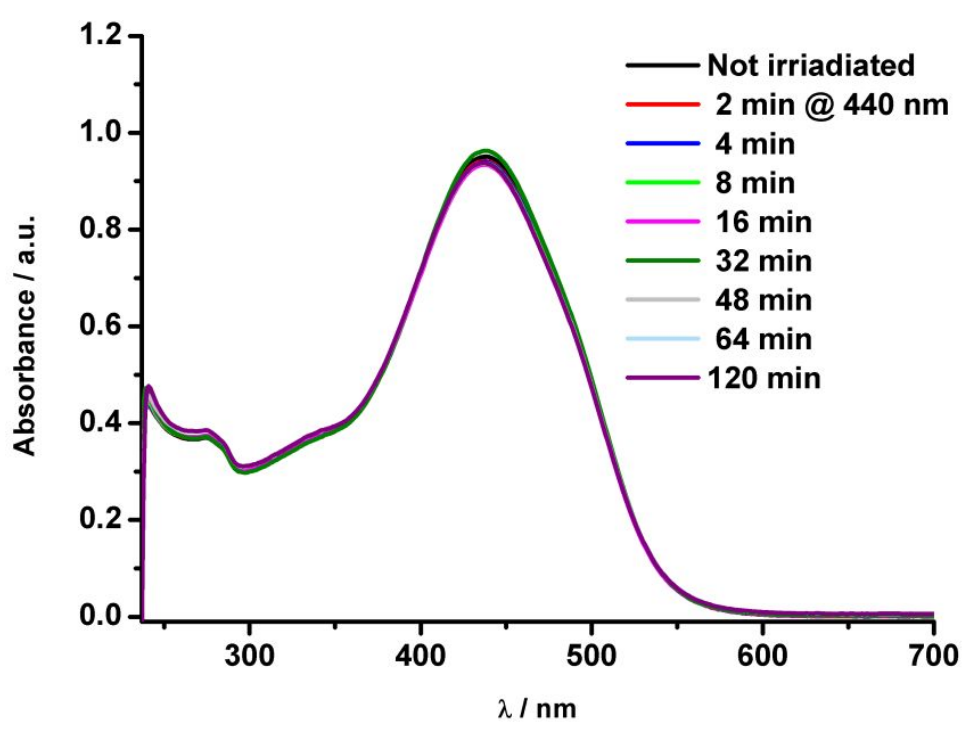

Figure 13. UV change in the absorption spectra of a $0.025 \mathrm{~g} / \mathrm{L}$ solution of $\mathbf{P}(\mathbf{A B}-\mathbf{3 H T}$-borazine) polymer in $\mathrm{CHCl}_{3}$ under irradiation at $440 \mathrm{~nm}$ at r.t.

The good solubility of the P(AB-3HT-borazine) polymer in a variety of organic solvents allowed a detailed study of its solvatochromic behavior. Thus, in order to get insight into the ICT nature of the P(AB-3HT-borazine) polymer, the solvent-dependent absorption and emission profiles (Fig. 14) were recorded in cyclohexane (dielectric permittivity $\varepsilon=2.02)$, toluene $(\varepsilon=2.38)$, THF ( $\varepsilon=7.58), \mathrm{CHCl}_{3}(\varepsilon=4.81), \mathrm{MeOH}(\varepsilon=32.7), \mathrm{MeCN}$ $(\varepsilon=37.5)$ and DMSO $(\varepsilon=46.7)$. A slight red shift was observed in the absorption band maxima accompanied by a broadening of the spectra when passing from nonpolar to polar solvents (Fig. 14a). ${ }^{34}$ However, changes in the emission spectra are more pronounced (Fig. 14b), with the polymer emitting at $660 \mathrm{~nm}$ and $720 \mathrm{~nm}$. It is worthy to note that no significant differences were found between protic and aprotic solvents, suggesting that the hydrogen-bonding interaction is not responsible for the red shift. The significant solvent-induced fluorescence quenching could be explained either by an excited-state photo-induced intramolecular charge-transfer (ICT) or by internal energy transfer (IET) or even both phenomena taking place between the borazine and thiophene units.
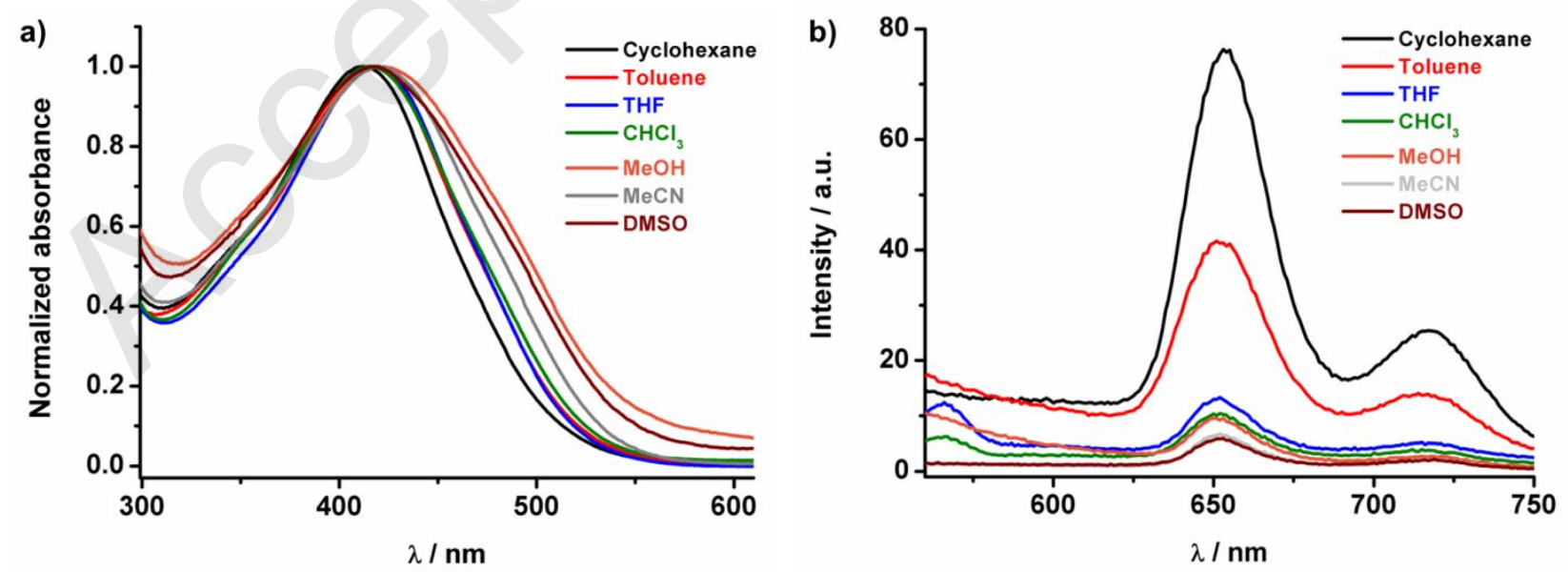

Figure 14. Absorption (a) and emission (b) spectra of the P(AB-3HT-borazine) polymer in various solvents of different polarities $\left(\lambda_{\mathrm{exc}}=416 \mathrm{~nm}\right)$. 
Cyclic voltammetry (CV) was used to investigate the electrochemical properties of the polymer P(AB-3HT-borazine), along with that of its monomeric precursors bis-OTf-borazine 9 and AB-3HT-(BPin) 221 in a solution of $n-\mathrm{Bu}_{4} \mathrm{NPF}_{6}(0.2 \mathrm{M})$ in $\mathrm{CH}_{2} \mathrm{Cl}_{2}$. As shown in Figure 15, the oxidation of borazine 9 is observed at a more anodic potential than that of the polymer and the thiophene 21. Its oxidation peak is observed around $1.6 \mathrm{~V}$ and its $\mathrm{HOMO}$ is determined at $-5.8 \mathrm{eV}$ from its onset oxidation potential $E_{\text {onset }}{ }^{\text {ox }}$ measured at $1.4 \mathrm{~V}$. No reduction was observed before the reduction of the electrolytic medium, suggesting that this borazine has a LUMO energy level higher than $-1.9 \mathrm{eV}$. The $\mathrm{CV}$ recorded for the AB-3HT-(BPin) 2 21, presents reversible oxidation and

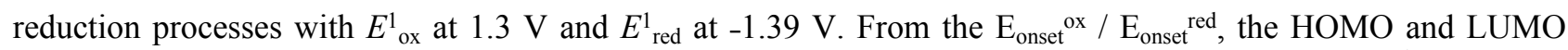
energy levels of AB-3HT-(BPin) 21 were determined to be at $-5.58 \mathrm{eV}$ and $-3.17 \mathrm{eV}$, respectively, resulting in an electrochemical bandgap of $2.41 \mathrm{eV}$. The CV trace of the P(AB-3HT-borazine) polymer exhibited a weakly reversible oxidation (at a lowest potential value than that of the two precursors) and an irreversible reduction wave with $E_{\text {ox }}^{1}$ and $E_{\text {red }}^{1}$ at $1.24 \mathrm{~V}$ and $-1.78 \mathrm{~V}$, respectively. The HOMO and LUMO energy levels were calculated to be $-5.36 \mathrm{eV}$ and $-3.08 \mathrm{eV}$, respectively, from their onset oxidation/reduction potential values. The electrochemical band gap was calculated to be $2.28 \mathrm{eV}$, which is slightly lower than that observed for the thiophene precursors, indicating a higher conjugation length in the polymer (see also the optical band gap of $2.27 \mathrm{eV}$ ).

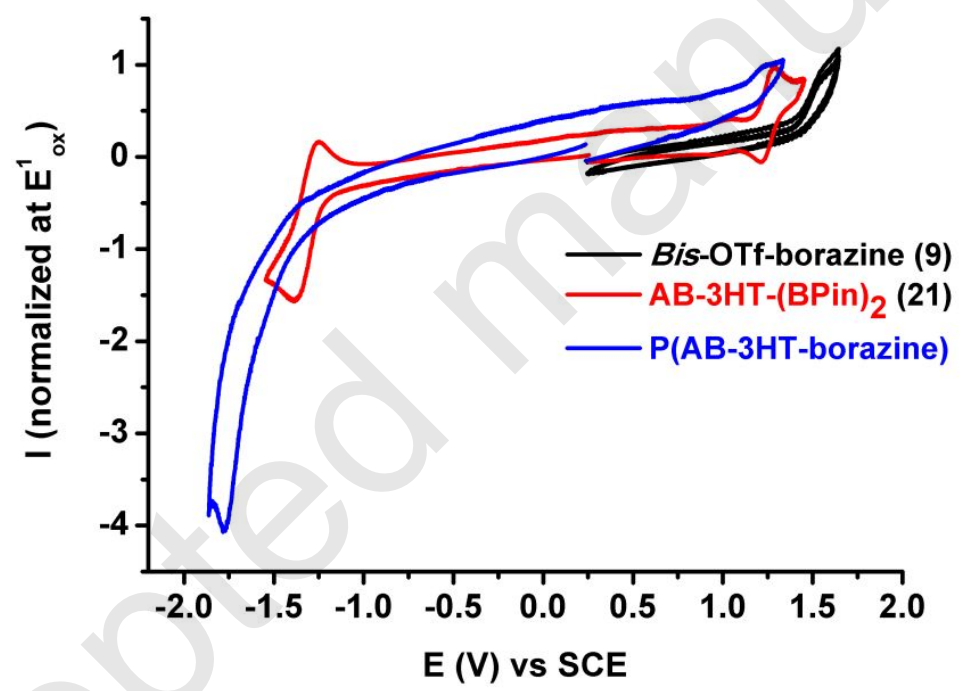

Figure 15. Cyclic voltammograms $(\mathrm{CV})$ recorded in $\mathrm{CH}_{2} \mathrm{Cl}_{2}, n-\mathrm{Bu}_{4} \mathrm{NPF}_{6}(0.2 \mathrm{M})$, using a platinum disk working electrode $(\varnothing 1 \mathrm{~mm})$ at a scan rate of $100 \mathrm{mV} / \mathrm{s}, \mathrm{Al}_{2} \mathrm{O}_{3}$ was added to the electrolytic medium to remove water traces. CV traces of bis-OTf-borazine 9 in black, AB-3HT-(BPin) 21 in red and polymer P(AB-3HT-borazine) in blue.

\section{CONCLUSIONS}

Owing to the possibility of functionalizing borazine cores with different groups on the aryl substituents at the $N$ and $B$ atoms, in this paper we reported the use of the borazine core as a modular scaffold to prepare photoactive hybrid BNC by means of the Pd-catalysed Suzuki cross-coupling reaction from the versatile tris-OTf-borazine derivative (4). Following this approach, we developed molecular BNC hybrid molecular scaffolds that, decorated with three azobenzene moieties, displayed reversible $E / Z$ photoisomerization. The chemical structure was unveiled by X-ray diffraction analysis. The photoswitching properties of azo-borazine-3 have been investigated by means of UV/VIS spectroscopy and exhibits efficient reversible $E / Z$ isomerization in toluene. To further 
explore the chemical versatility of the borazine core, the new BN-doping polythiophene-type polymer P(AB-3HT-borazine) incorporating the borazine core, azobenzene and 3HT skeletons was also developed through Suzuki-type cross-coupling polycondensation reaction. Thermal, optical and electrochemical properties were investigated. In particular, emission studies in solvents of different polarity, suggested that the polymer undergoes intramolecular charge-transfer (ICT). This work opens the gate of applying the rapidly developing borazine chemistry as a new toolbox for engineering functional materials with tailored and exploitable optoelectronic properties.

\section{EXPERIMENTAL SECTION}

General Experimental Methods. Adsorption silica chromatography columns (SCC) were performed using Merck Gerduran silica gel 60 (particle size $40-60 \mu \mathrm{m}$ ). NMR spectra $\left({ }^{1} \mathrm{H},{ }^{13} \mathrm{C}\right.$ NMR, ${ }^{11} \mathrm{~B}$ and ${ }^{19} \mathrm{~F}$ NMR) were recorded on a $400 \mathrm{MHz}$ (Jeol JNM EX-400) or 500 MHz NMR (Jeol JNM ECZR-500) spectrometer. Chemical shifts are reported in parts per million $(\mathrm{ppm})$ using the solvent residual signal as an internal reference $\left(\mathrm{CDCl}_{3} \delta_{\mathrm{H}}=\right.$ $\left.7.26 \mathrm{ppm}, \delta_{\mathrm{C}}=77.16 \mathrm{ppm} ; \mathrm{CD}_{2} \mathrm{Cl}_{2} \delta_{\mathrm{H}}=5.32 \mathrm{ppm}, \delta_{\mathrm{C}}=54.00 \mathrm{ppm} ;\left(\mathrm{CD}_{3}\right)_{2} \mathrm{SO} \delta_{\mathrm{H}}=2.50 \mathrm{ppm}, \delta_{\mathrm{C}}=39.52 \mathrm{ppm}\right)$. For ${ }^{11} \mathrm{~B}$, chemical shifts are reported in $\mathrm{ppm}$ downfield from $\mathrm{BF}_{3} \cdot \mathrm{OEt}_{2}$ as internal reference, and analyses were performed in quartz tubes. Resonance multiplicity is described as s (singlet), $\mathrm{d}$ (doublet), $\mathrm{t}$ (triplet), $\mathrm{q}$ (quartet), quin (quintet), m (multiplet), br (broad signal), dd (doublet of doublets). Carbon spectra were acquired with a complete decoupling for the proton. All spectra were recorded at $25{ }^{\circ} \mathrm{C}$ unless specified otherwise. Infrared spectra (IR) were recorded on a Perkin-Elmer Spectrum II FTIR System UATR, mounted with a diamond crystal. Selected absorption bands are reported in wavenumber $\left(\mathrm{cm}^{-1}\right)$. (i) ESI mass spectra (HRMS) were performed on a Waters QToF2 or on a Bruker maXis Q-ToF mass spectrometer operating in positive mode at Centre de spectrométrie de masse of University of Mons and the "Fédération de Recherche" ICOA/CBM (FR2708) platform of Orléans in France. (ii) High-resolution MALDI mass spectra (HRMS) were performed on a Waters QToF Premier mass spectrometer at Centre de spectrométrie de masse of University of Mons. Melting points (Mp) were measured on a Büchi Melting Point B-545 apparatus in an open capillary and have not been corrected. Light irradiation experiments were performed with monochromatic light produced with a LOT Oriel equipment, consisting of a $1000 \mathrm{~W}$ Xe lamp (LSB551 ozone free) connected via an axial optical path to a computer-controlled monochromator MSH-300. The $180^{\circ}$ optical path was composed of a condenser lens, which collimated the light emitted from the source, and a focusing lens aligned to the monochromator entrance slit. The entrance and the exit slits of the monochromator were adjusted in order to have a $20 \mathrm{~nm}$ bandwidth output light. The sample was placed in the collimated beam of the monochromatic light. UV-vis absorption spectra were recorded on a Varian Cary 5000 UV-Vis-NIR spectrophotometer, using quartz cells with a path length of $1.0 \mathrm{~cm}$. Emission spectra were recorded on a Cary-Varian Eclipse fluorescence spectrophotometer recorded using quartz cuvettes. All photophysical experiments were carried out in air-equilibrated solutions otherwise stated. Data collections were performed at the X-ray diffraction beamline (XRD1) of the Elettra Synchrotron, Trieste (Italy) ${ }^{35}$, using a Pilatus 2M hybrid-pixel area detector (DECTRIS Ltd., Baden-Daettwil, Switzerland). Complete datasets were collected at $100 \mathrm{~K}$ (nitrogen stream supplied through an Oxford Cryostream 700) with a monochromatic wavelength of 0.700 $\AA$ through the rotating crystal method. The crystals of compounds were dipped in N-paratone and mounted on the goniometer head with kapton loops (MiTeGen, Ithaca, USA). Complete datasets for $\mathbf{4}$ and $\mathbf{3}$ have been obtained 
merging two different data collections done on the same crystal, mounted with different orientations. The diffraction data were indexed, integrated and scaled using XDS. ${ }^{36}$ The structures were solved by direct methods implemented in the Sir2014 code. ${ }^{37}$ Fourier analysis and refinement were performed by the full-matrix least-squares based on $\mathrm{F}^{2}$ implemented in SHELXL-2018/3. ${ }^{38}$ The Coot program was used for modeling. ${ }^{39}$ Anisotropic thermal motion was then applied to all atoms with occupancy greater than $75 \%$. Hydrogen atoms were included at calculated positions with isotropic $\mathrm{U}_{\text {factors }}=1.2 \cdot \mathrm{U}_{\text {eq }}$ or $\mathrm{U}_{\text {factors }}=1.5 \cdot \mathrm{U}_{\text {eq }}$ for methyl groups $\left(\mathrm{U}_{\text {eq }}\right.$ being the equivalent isotropic thermal factor of the bonded non hydrogen atom). Restrains on bond lengths, angles and thermal motions (DFIX, DANG, SIMU and DELU) have been applied on disordered fragments. Essential crystal and refinement data are reported in the supporting information document (Table S1). Size exclusion chromatography (SEC or GPC) was performed in THF (with $2 \%$ triethylamine added) at $35^{\circ} \mathrm{C}$ using a Polymer Laboratories liquid chromatograph equipped with a PL-DG802 degasser, an isocratic HPLC pump LC 1120 (flow rate $\left.=1 \mathrm{~mL} \cdot \mathrm{min}^{-1}\right)$, a Marathon autosampler $\left(\right.$ loop volume $=200 \mu \mathrm{L}$, solution conc. $\left.=1 \mathrm{mg} \cdot \mathrm{mL}^{-1}\right)$, a PL-DRI refractive index detector and three columns: a PL gel $10 \mu \mathrm{m}$ guard column and two PL gel Mixed-B $10 \mu \mathrm{m}$ columns (linear columns for separation of MWPS ranging from 500 to 106 daltons). Poly(styrene) standards were used for calibration. Cyclic voltammetry was recorded against saturated calomel electrode (SCE) in $\mathrm{CH}_{2} \mathrm{Cl}_{2}-n-\mathrm{Bu}_{4} \mathrm{NPF}_{6}(0.2 \mathrm{M})$ using a platinum disk working electrode $(\varnothing 1.0 \mathrm{~mm})$ at a scan rate of $100 \mathrm{mV} . \mathrm{s}^{-1}$. $\mathrm{Al}_{2} \mathrm{O}_{3}$ was added to the electrolytic medium to avoid any water traces. Chemicals were purchased from Sigma Aldrich, Acros Organics, Fluorochem, TCI, VWR, carbosynth, and ABCR, and were used as received, unless otherwise stated. Solvents were purchased from Sigma Aldrich, Acros Organics and VWR, and deuterated solvents were purchased from Eurisotop. THF was distilled from Na/benzophenone and stored on activated $3 \AA$ molecular sieves 24 hours prior to use and toluene were distilled from $\mathrm{CaH}_{2}$ and stored on activated $3 \AA$ molecular sieves 24 hours prior to use. Aniline was purified by distillation from $\mathrm{Sn}$ powder, followed by distillation from $\mathrm{Zn}$ powder, followed by distillation from $\mathrm{CaH}_{2}$ under inert atmosphere, yielding a transparent colorless liquid stored protected from light under argon. Anhydrous conditions, when necessary, were achieved by keeping all glassware in the oven at $120^{\circ} \mathrm{C}$ overnight and then allowed to cool down under a vacuum followed by drying the two-neck flask by flaming with a heat gun under a vacuum and purging with $\mathrm{N}_{2}$. The inert atmosphere was maintained using $\mathrm{N}_{2}$-filled balloons equipped with a syringe and needle that was used to penetrate the rubber stoppers used to close the flask's necks.

4-bromo-3,5-di-methylaniline (5'). To a solution of distillated 3,5-di-methylaniline 4' (1.2 $\mathrm{mL}, 10 \mathrm{mmol}$ ) in anhydrous DMF $(10 \mathrm{~mL})$ was added dropwise a solution of $N$-bromosuccinimide (NBS) $(1.8 \mathrm{~g}, 10 \mathrm{mmol})$ in anhydrous DMF $(10 \mathrm{~mL})$ at $0{ }^{\circ} \mathrm{C}$. The reaction mixture was stirred at r.t. for $24 \mathrm{~h}$. The crude is extracted with $\mathrm{CH}_{2} \mathrm{Cl}_{2}$, and the organic phases are dried over $\mathrm{MgSO}_{4}$ and evaporated yielding a brown solid, purified by column chromatography (cyclohexane/EtOAc 0 to $20 \%$ ) to the desired product 5' as a white solid (1.6 g, 80\%). Mp: 72.7 - $74.1{ }^{\circ} \mathrm{C} .{ }^{1} \mathrm{H} \mathrm{NMR}\left(\mathrm{CDCl}_{3}, 400 \mathrm{MHz}\right): \delta 2.32$ (s, $\left.6 \mathrm{H}\right), 3.54$ (s, $\left.2 \mathrm{H}\right), 6.44(\mathrm{~s}, 2 \mathrm{H}) .{ }^{13} \mathrm{C}\left\{{ }^{1} \mathrm{H}\right\} \mathrm{NMR}\left(\mathrm{CDCl}_{3}, 101\right.$ MHz): $\delta 24.0,115.2,116.0,139.0,145.1$. FTIR (UATR) $v\left(\mathrm{~cm}^{-1}\right): 3403,3307,2953,2916,1623,1586$. HRMS (EI-ToF) m/z: [M] Calcd for $\mathrm{C}_{8} \mathrm{H}_{10} \mathrm{BrN}^{+}$; 198.9997; Found, 198.9998.

N,N'-di-allyl-4-bromo-3,5-di-methylaniline (6') and N,N'-di-benzyl-4-bromo-3,5-di-methylaniline 4-bromo-3,5-dimethylaniline (1.001 g, $5 \mathrm{mmol}$ ), $\mathrm{NaHCO}_{3}(1.2605 \mathrm{~g}, 15 \mathrm{mmol})$ and sodium dodecyl sulfate (SDS) $(20 \mathrm{mg})$ were dispersed in a mixture of $\mathrm{EtOH}$ and $\mathrm{H}_{2} \mathrm{O}(2: 5 \mathrm{v} / \mathrm{v})(30 \mathrm{~mL}) . \mathrm{R}-\mathrm{Br}(\mathrm{R}=$ Allyl or $\mathrm{R}=\mathrm{Bn})(1 \mathrm{~mL}, 11.6$ 
mmol) was added dropwise to the mixture. The reaction was carried out at $80{ }^{\circ} \mathrm{C}$ for $16 \mathrm{~h}$. The reaction mixture was diluted with $\mathrm{CH}_{2} \mathrm{Cl}_{2}$, washed with brine and water, dried over $\mathrm{MgSO}_{4}$ and evaporated to yield brownish oil. Column chromatography (cyclohexane) purification afforded the desired product 6'and 7' as transparent oil (1.34 g, 96\%) and white solid (1.52 g, 80\%), respectively.

N,N'-diallyl-4-bromo-3,5-dimethylaniline (6'). ${ }^{1} \mathrm{H}$ NMR $\left(\mathrm{CDCl}_{3}, 400 \mathrm{MHz}\right): \delta 2.43(\mathrm{~s}, 6 \mathrm{H}), 3.95(\mathrm{~m}, 4 \mathrm{H})$, 5.22-5.26 (m, $4 \mathrm{H}), 5.91(\mathrm{~m}, 2 \mathrm{H}), 6.52(\mathrm{~s}, 2 \mathrm{H}) .{ }^{13} \mathrm{C}\left\{{ }^{1} \mathrm{H}\right\} \mathrm{NMR}\left(\mathrm{CDCl}_{3}, 101 \mathrm{MHz}\right): \delta 24.4,52.8,112.5,114.1$, 116.1, 133.8, 138.38, 147.4. FTIR (UATR) $v\left(\mathrm{~cm}^{-1}\right): 3078,2917,2979,1642,1588,1476,1376,1417,1279$, 1199, 994, 918, 823, 737. HRMS (ESI-ToF) m/z: [M] ${ }^{+}$Calcd for $\mathrm{C}_{14} \mathrm{H}_{18} \mathrm{BrN}^{+}$, 279.0623; Found 279.0620.

N,N'-di-benzyl-4-bromo-3,5-di-methylaniline (7'). Mp: 119.2-121.4 ${ }^{\circ} \mathrm{C} .{ }^{1} \mathrm{H} \mathrm{NMR}\left(\mathrm{CDCl}_{3}, 400 \mathrm{MHz}\right): \delta 2.29(\mathrm{~s}, 6$ $\mathrm{H}), 4.59(\mathrm{~s}, 4 \mathrm{H}), 6.49(\mathrm{~s}, 2 \mathrm{H}), 7.21(\mathrm{~m}, 4 \mathrm{H}), 7.35(\mathrm{~m}, 6 \mathrm{H}) .{ }^{13} \mathrm{C}\left\{{ }^{1} \mathrm{H}\right\} \mathrm{NMR}\left(\mathrm{CDCl}_{3}, 101 \mathrm{MHz}\right): \delta 24.4,54.0$, 112.5, 114.6, 126.8, 127.1, 128.8, 138.4, 138.7, 148.0. FTIR (UATR) $v\left(\mathrm{~cm}^{-1}\right)$ : 3026.59, 2917.93, 1591.86, 1200.17, 1073.88, 1026.88. HRMS (ESI-ToF) m/z: [M] ${ }^{+}$Calcd for $\mathrm{C}_{22} \mathrm{H}_{22} \mathrm{BrN}^{+}$, 379.0936; Found 379.0935.

Allyl-borazine (9') and Benzyl-borazine (10'). Following the general procedure for borazine synthesis': aniline $(0.28 \mathrm{~mL}, 3.0 \mathrm{mmol})$ was used in anhydrous toluene $(8 \mathrm{~mL})$ with $\mathrm{BCl}_{3}(1 \mathrm{M}$ in heptane, $2.7 \mathrm{~mL}, 2.64 \mathrm{mmol})$. $\mathrm{Ar}-\mathrm{Li}$ is prepared as nucleophile from $N, N^{\prime}$-di-allyl-4-bromo-3,5-di-methylaniline 6' or $N, N^{\prime}$-di-benzyl-4-bromo-3,5-di-methylaniline $7^{\prime}(0.681 \mathrm{~g}, 2.42 \mathrm{mmol})$ in anhydrous THF (10 mL) with tert-BuLi (1.7 $\mathrm{M}$ in pentane, $2.92 \mathrm{~mL}, 4.96 \mathrm{mmol})$. The yellow suspension was stirred at r.t. for $16 \mathrm{~h}$. Solvents were removed under reduced pressure giving brown solid. Precipitation in cold $\mathrm{MeOH}$ yielded the desired compound Allyl-borazine 9' and Benzyl-borazine 10' as white solids (0.32 g, 35\%) and (0.84 g, 70\%), respectively.

Allyl-borazine (9'). Mp: 195.5-196.9 ${ }^{\circ} \mathrm{C},{ }^{1} \mathrm{H}$ NMR $\left(\mathrm{CDCl}_{3}, 400 \mathrm{MHz}\right): \delta 2.14$ (s, $\left.18 \mathrm{H}\right), 3.65$ (d, $\left.12 \mathrm{H}\right), 4.92-5.02$ $(\mathrm{q}, 12 \mathrm{H}), 5.65(\mathrm{~m}, 6 \mathrm{H}), 5.93(\mathrm{~s}, 6 \mathrm{H}), 6.67-6.75(\mathrm{~m}, 15 \mathrm{H}) .{ }^{13} \mathrm{C}\left\{{ }^{1} \mathrm{H}\right\} \mathrm{NMR}\left(\mathrm{CDCl}_{3}, 101 \mathrm{MHz}\right): \delta 23.6,52.4$, $111.0,115.9,123.6,126.5,127.6,134.7,138.4,146.9,148.2$. Signal for carbon atom attached to boron atom is missing due to quadrupolar relaxation. ${ }^{11} \mathrm{~B} \mathrm{NMR}\left(\mathrm{CDCl}_{3}, 128 \mathrm{MHz}\right): \delta 36.2$ (br). FTIR (UATR) $v\left(\mathrm{~cm}^{-1}\right): 3024$, 2913, 1642, 1598, 1491, 1350. HRMS (MALDI-ToF) m/z: [M] $]^{+}$Calcd for $\mathrm{C}_{60} \mathrm{H}_{69} \mathrm{~B}_{3} \mathrm{~N}_{6}{ }^{+}$, 906.5863; Found 906.5854.

Benzyl-borazine (10'). Mp: 229.8-231.8 ${ }^{\circ} \mathrm{C} .{ }^{1} \mathrm{H}$ NMR $\left(\mathrm{CDCl}_{3}, 400 \mathrm{MHz}\right): \delta 2.15$ (s, $\left.18 \mathrm{H}\right), 4.35$ (s, $\left.12 \mathrm{H}\right), 6.03$ (s, $6 \mathrm{H}), 6.87(\mathrm{~m}, 15 \mathrm{H}), 7.02-7.04(\mathrm{~m}, 12 \mathrm{H}), 7.19-7.28(\mathrm{~m}, 18 \mathrm{H}) .{ }^{13} \mathrm{C}\left\{{ }^{1} \mathrm{H}\right\} \mathrm{NMR}\left(\mathrm{CDCl}_{3}, 101 \mathrm{MHz}\right): \delta 23.7,53.8$, $110.7,124.1,126.9,127.1,127.4,127.7,128.67,139.1,139.5$. Signal for carbon atom attached to boron atom is missing due to quadrupolar relaxation. ${ }^{11} \mathrm{~B} \mathrm{NMR}\left(\mathrm{CDCl}_{3}, 128 \mathrm{MHz}\right): \delta 36.1$ (br). FTIR (UATR) $v\left(\mathrm{~cm}^{-1}\right): 3057$, 1600, 1492, 1394, 1351, 1273, 1202, 1170, 1028, 964, 845, 728, 697. HRMS (ESI-ToF) m/z: $[\mathrm{M}+\mathrm{H}]^{+} \mathrm{Calcd}$ for $\mathrm{C}_{84} \mathrm{H}_{82} \mathrm{~B}_{3} \mathrm{~N}_{6}{ }^{+}, 1207.6875$; Found 1207.6841.

Tri-amino-borazine (11'). Benzyl-borazine (10') $(797.7 \mathrm{mg}, 0.66 \mathrm{mmol})$ was dissolved in a mixture of $\mathrm{CH}_{2} \mathrm{Cl}_{2}$ and $\mathrm{MeOH}(85: 15 \mathrm{v} / \mathrm{v})(30 \mathrm{~mL}) . \mathrm{Pd}(\mathrm{OH})_{2} / \mathrm{C}(20 \%, 161.1 \mathrm{mg}, 1.14 \mathrm{mmol})$ was added to the solution. The suspension was hydrogenated with $\mathrm{H}_{2}(1 \mathrm{~atm})$ at r.t. for $24 \mathrm{~h}$. The crude was filtrated on celite pad and evaporated to a brown residue purified on neutral alumina plug $(\mathrm{MeOH})$ yielding tri-amino-borazine 11' as a white powder (0.42 g, 95 \%). Mp: decomposition before melting around $150{ }^{\circ} \mathrm{C} .{ }^{1} \mathrm{H} \mathrm{NMR}\left(\mathrm{CDCl}_{3}, 400 \mathrm{MHz}\right): \delta 2.19(\mathrm{~s}, 18 \mathrm{H})$, $6.00(\mathrm{~s}, 6 \mathrm{H}), 6.67(\mathrm{t}, 3 \mathrm{H}), 6.74(\mathrm{t}, 6 \mathrm{H}), 6.86-6.88(\mathrm{~d}, 6 \mathrm{H}) .{ }^{13} \mathrm{C}\left\{{ }^{1} \mathrm{H}\right\} \mathrm{NMR}\left(\mathrm{CDCl}_{3}, 101 \mathrm{MHz}\right): \delta 23.6,114.8$, 
$125.1,127.7,128.4,139.6,146.6,148.2$. Signal for carbon atom attached to boron atom is missing due to quadrupolar relaxation. ${ }^{11} \mathrm{~B}$ NMR $\left(\mathrm{CDCl}_{3}, 128 \mathrm{MHz}\right): \delta 36.9$ (br). FTIR (UATR) $v\left(\mathrm{~cm}^{-1}\right): 2913,1599,1491$, 1491, 1452, 1355, 1307, 1164, 1074, 1026, 842, 746, 699. HRMS (ESI-ToF) m/z: [M] Calcd for $\mathrm{C}_{42} \mathrm{H}_{45} \mathrm{~B}_{3} \mathrm{~N}_{6}{ }^{+}$, 666.3985; Found 666.4021.

(4-bromo-3,5-dimethylphenoxy)(tert-butyl)dimethylsilane (2). 4-bromo-3,5-dimethylphenol (6.28 g, $31.20 \mathrm{mmol})$ and imidazole $(6.35 \mathrm{~g}, 93.3 \mathrm{mmol})$ were dissolved in DMF $(80 \mathrm{~mL})$ and tert-butyldimethylsilyl chloride (TBDMSCl) $(6.6 \mathrm{~g}, 43.68 \mathrm{mmol})$ was added. The reaction was carried out at $50{ }^{\circ} \mathrm{C}$ for $16 \mathrm{~h}$. The reaction mixture was cooled down to r.t. and extracted with $\mathrm{CH}_{2} \mathrm{Cl}_{2}(3 \times 60 \mathrm{~mL})$. The organic phase was dried over $\mathrm{MgSO}_{4}$ and evaporated under reduced pressure at $70{ }^{\circ} \mathrm{C}$ to remove residues of TBDMSCl yielding molecule 2 as translucent oil (9.25 g, 94\%). ${ }^{1} \mathrm{H}$ NMR ( $\left.\mathrm{CDCl}_{3}, 400 \mathrm{MHz}\right): \delta 0.21$ (s, $\left.6 \mathrm{H}\right), 1.00$ (s, $\left.9 \mathrm{H}\right), 2.37$ (s, $\left.6 \mathrm{H}\right), 6.60$ (m, 2 H). ${ }^{13} \mathrm{C}\left\{{ }^{1} \mathrm{H}\right\}$ NMR $\left(\mathrm{CDCl}_{3}, 100 \mathrm{MHz}\right): \delta-4.3,18.3,24.0,25.8,119.1,120.0,139.1,154.2$. FTIR (UATR) $v\left(\mathrm{~cm}^{-1}\right)$ : 2955, 2929, 2858, 1582, 1464, 1410, 1362, 1321, 1252, 1167, 1031, 1020, 978, 834, 779, 696, 673. HRMS (ESI-ToF) $\mathrm{m} / \mathrm{z}$ : $[\mathrm{M}+\mathrm{H}]^{+}$Calcd for $\mathrm{C}_{14} \mathrm{H}_{24} \mathrm{BrOSi}^{+}$, 315.0774; Found 315.0771. Characterization is in accordance with data reported in the literature. ${ }^{10}$

Tri-B-(2,6-dimethyl-4-(O-TBDMS)-phenyl)-tri-N-phenyl-borazine (3). Aniline (0.61 mL, $6.6 \mathrm{mmol})$ was used in anhydrous toluene $(8 \mathrm{~mL})$ with $\mathrm{BCl}_{3}(1 \mathrm{M}$ in heptane, $8 \mathrm{~mL}, 7.92 \mathrm{mmol})$. Ar-Li is prepared as nucleophile from 4-bromo-3,5-dimethylphenoxy)(tert-butyl)dimethylsilane 2 (2.46 g, $7.8 \mathrm{mmol})$ in anhydrous THF (20 mL) with tert-BuLi (1.7 M in pentane, $10.1 \mathrm{~mL}, 17.16 \mathrm{mmol})$. The yellow suspension was stirred at r.t. for $16 \mathrm{~h}$. Solvents were removed under reduced pressure affording pale yellow solid. The mixture was poured in water $(30 \mathrm{~mL})$ and extracted with $\mathrm{CH}_{2} \mathrm{Cl}_{2}(3 \times 30 \mathrm{~mL})$. The organic phase was dried over $\mathrm{MgSO}_{4}$ and evaporated. The crude was precipitated from cold $\mathrm{MeOH}$ to yield molecule 3 as white powder $(1.1 \mathrm{~g}, 49 \%)$. Mp: $205-207{ }^{\circ} \mathrm{C}$. ${ }^{1} \mathrm{H}$ NMR $\left(\mathrm{CDCl}_{3}, 400 \mathrm{MHz}\right): \delta-0.04(\mathrm{~s}, 18 \mathrm{H}), 0.84(\mathrm{~s}, 27 \mathrm{H}), 2.19(\mathrm{~s}, 18 \mathrm{H}), 6.06(\mathrm{~m}, 6 \mathrm{H}), 6.68-6.79(\mathrm{~m}, 15 \mathrm{H}) .{ }^{13} \mathrm{C}\left\{{ }^{1} \mathrm{H}\right\}$ NMR $\left(\mathrm{CDCl}_{3}, 100 \mathrm{MHz}\right): \delta-4.4,18.3,23.1,25.9,117.7,124.12$ 126.8, 127.2, 139.0, 146.3, 154.6. Signal for carbon atom attached to boron atom is missing due to quadrupolar relaxation. ${ }^{11} \mathrm{~B} \mathrm{NMR}\left(\mathrm{CDCl}_{3}, 128 \mathrm{MHz}\right): \delta$ 36.4 (br). FTIR (UATR) $v\left(\mathrm{~cm}^{-1}\right):$ 3040, 2929, 1597, 1491, 1463, 1357, 1251, 1151, 1075, 1038, 1005, 968, 905 , 866, 848, 836, 814, 736, 684. HRMS (ESI-ToF) m/z: [M+H] $]^{+}$Calcd for $\mathrm{C}_{60} \mathrm{H}_{85} \mathrm{~B}_{3} \mathrm{~N}_{3} \mathrm{O}_{3} \mathrm{Si}_{3}{ }^{+}$, 1012.6172; Found 1012.6193. Characterization is in accordance with data reported in the literature. ${ }^{10}$

Tris-OTf-borazine (4). Tri-B-(2,6-dimethyl-4-(O-TBDMS)-phenyl)-tri- $N$-phenyl-borazine 3 (736.1 mg, 0.73 mmol) was dissolved in anhydrous THF (20 mL). TBAF (1 M in THF, $0.8 \mathrm{~mL}, 0.803 \mathrm{mmol})$ was added dropwise at $0{ }^{\circ} \mathrm{C}$, a white precipitate was formed in a yellowish solution. The reaction mixture was stirred at r.t. for $2 \mathrm{~h}$. The precipitate was then filtrated off and washed with THF $(3 \times 30 \mathrm{~mL})$. The obtained solid was dried under vacuum and used in the followed step without further purification. The obtained off-white solid from the step one (478.8 $\mathrm{mg}, 0.71 \mathrm{mmol})$ was dissolved in pyridine $(30 \mathrm{~mL})$ and triflic anhydride $\left(\mathrm{Tf}_{2} \mathrm{O}\right)(12 \mathrm{eq} ., 1.6 \mathrm{~mL}, 8.52 \mathrm{mmol}) \mathrm{was}$ added dropwise at $0{ }^{\circ} \mathrm{C}$. The brownish solution was stirred at r.t. for $15 \mathrm{~h}$. Solvents were removed under reduced pressure giving brown solid extracted with $\mathrm{CH}_{2} \mathrm{Cl}_{2}(3 \mathrm{x} 50 \mathrm{~mL})$. Purified by column chromatography (cyclohexane $/ \mathrm{CH}_{2} \mathrm{Cl}_{2}, 8: 2 \mathrm{v} / \mathrm{v}$ ) affording the desired compound 4 as a white powder $(0.583 \mathrm{~g}, 75 \%)$ Mp: 236-238 ${ }^{\circ} \mathrm{C} .{ }^{1} \mathrm{H}$ NMR $\left(\mathrm{CDCl}_{3}, 400 \mathrm{MHz}\right): \delta 2.32$ (s, $\left.18 \mathrm{H}\right), 6.49$ (s, $\left.6 \mathrm{H}\right), 6.75-6.77$ (m, $\left.6 \mathrm{H}\right), 6.80-6.82(\mathrm{~m}, 9 \mathrm{H})$. ${ }^{13} \mathrm{C}\left\{{ }^{1} \mathrm{H}\right\} \mathrm{NMR}\left(\mathrm{CDCl}_{3}, 100 \mathrm{MHz}\right): \delta 23.2,27.0,118.1,120.3,125.5,126.4,127.5,140.4,144.8,149.2$. Signal for 
carbon atom attached to boron atom is missing due to quadrupolar relaxation. ${ }^{19} \mathrm{~F}$ NMR $\left(\mathrm{CDCl}_{3}, 376 \mathrm{MHz}\right): \delta$ -72.76 (s). ${ }^{11} \mathrm{~B}$ NMR $\left(\mathrm{CDCl}_{3}, 128 \mathrm{MHz}\right): \delta 35.7$ (br). FTIR (UATR): $v\left(\mathrm{~cm}^{-1}\right)$ 2924, 1590, 1492, 1419, 1364, 1240, 1207, 1121, 1013, 946, 845, 813, 769, 702. HRMS (ESI-ToF) m/z: $[\mathrm{M}+\mathrm{H}]^{+}$Calcd for $\mathrm{C}_{45} \mathrm{H}_{40} \mathrm{~B}_{3} \mathrm{~F}_{9} \mathrm{~N}_{3} \mathrm{O}_{9} \mathrm{~S}_{3}{ }^{+}$, 1066.2057; Found 1066.2067. Characterization is in accordance with data reported in the literature. ${ }^{10}$

(E)-1-(4-iodophenyl)-2-phenyldiazene (7). Nitrosobenzene 5 (3.0 g, $28 \mathrm{mmol})$ and 4-iodoaniline 6 (6.13 g, 28.0 $\mathrm{mmol})$ were dissolved in acetic acid $(50 \mathrm{~mL})$. The mixture was stirred at r.t. for $18 \mathrm{~h}$. The reaction was quenched by water $(100 \mathrm{~mL})$ and the orange precipitate was filtered off and washed with water. The crude was purified by column chromatography (cyclohexane) affording the desired molecule 7 as an orange solid $(7.0 \mathrm{~g}, 81 \%)$. Mp: 98.2-100.4 ${ }^{\circ} \mathrm{C} .{ }^{1} \mathrm{H}$ NMR (DMSO, $400 \mathrm{MHz}$ ): $\delta$ 7.59-7.62 (m, $\left.3 \mathrm{H}\right), 7.67-7.69$ (m, $\left.2 \mathrm{H}\right), 7.89-792(\mathrm{~m}, 2 \mathrm{H})$, 7.98-8.00 (m, $2 \mathrm{H}) .{ }^{13} \mathrm{C}\left\{{ }^{1} \mathrm{H}\right\}$ NMR $\left(\mathrm{CDCl}_{3}, 100 \mathrm{MHz}\right): \delta 97.8,123.1,124.6,129.3,131.5 ; 138.5,152.0,152.6$. FTIR (UATR) $v\left(\mathrm{~cm}^{-1}\right): 3060,3041,2252,1917,1744,1576,1565,1474,1444,1393,1297,1221,1153,1070$, 1051, 1017, 928, 907, 834, 731, 705, 689, 627. HRMS (ESI-ToF) m/z: $[\mathrm{M}+\mathrm{H}]^{+}$Calcd for $\mathrm{C}_{12} \mathrm{H}_{10} \mathrm{~N}_{2} \mathrm{I}^{+}, 308.9883$; Found 308.9882.

(E)-1-phenyl-2-(4-(4,4,5,5-tetramethyl-1,3,2-dioxaborolan-2-yl)phenyl)diazene (E)-1-(4-iodophenyl)-2-phenyldiazene 7 (1.6 g, $5.2 \mathrm{mmol}), \mathrm{B}_{2} \mathrm{Pin}_{2}(1.98 \mathrm{~g}, 7.8 \mathrm{mmol}), \mathrm{KOAc}(1.02 \mathrm{~g}, 10.4 \mathrm{mmol})$ and $\left[\mathrm{Pd}(\mathrm{dppf}) \mathrm{Cl}_{2} \cdot \mathrm{CH}_{2} \mathrm{Cl}_{2}\right](0.1272 \mathrm{~g}, 0.156 \mathrm{mmol})$ were suspended in anhydrous DMF (degassed by 3 freeze-to-thaw cycles) $(20 \mathrm{ml})$. The reaction was carried out under argon at $90{ }^{\circ} \mathrm{C}$ for $18 \mathrm{~h}$. After cooling down to r.t., the reaction mixture was diluted with $\mathrm{CH}_{2} \mathrm{Cl}_{2}(60 \mathrm{~mL})$, washed with brine and $\mathrm{H}_{2} \mathrm{O}$, dried over $\mathrm{MgSO}_{4}$ and evaporated to a brown dark orange solid purified by column chromatography (cyclohexane $/ \mathrm{CH}_{2} \mathrm{Cl}_{2}$, from 0 to $20 \%$ ) yielding the desired compound 8 as an orange solid (1.3 g, 80\%). Mp: 93.5-94.7 ${ }^{\circ} \mathrm{C} .{ }^{1} \mathrm{H}$ NMR $\left(\mathrm{CD}_{2} \mathrm{Cl}_{2}, 400\right.$ MHz): $\delta 1.36$ (s, $12 \mathrm{H}), 7.51-7.56(\mathrm{~m}, 3 \mathrm{H}), 7.88-7.95$ (m, $6 \mathrm{H}) .{ }^{13} \mathrm{C}\left\{{ }^{1} \mathrm{H}\right\} \mathrm{NMR}\left(\mathrm{CD}_{2} \mathrm{Cl}_{2}, 100 \mathrm{MHz}\right): \delta 25.1,84.5$, 122.3, 123.3, 129.5, 131.7, 135.9, 153.1, 154.7. ${ }^{11} \mathrm{~B}$ NMR $\left(\mathrm{CD}_{2} \mathrm{Cl}_{2}, 128 \mathrm{MHz}\right): \delta 29.6$ (s). FTIR (UATR) $v(\mathrm{~cm}$ $\left.{ }^{-1}\right)$ : 3063, 2982, 2926, 1602, 1569, 1502, 1467, 1444, 1397, 1357, 1332, 1302, 1274, 1140, 1088, 1000, 963, 855. HRMS (ESI-ToF) m/z: [M+H] $]^{+}$Calcd for $\mathrm{C}_{18} \mathrm{H}_{22} \mathrm{BN}_{2} \mathrm{O}_{2}{ }^{+}, 309.1769$; Found 309.1773.

Azo-borazine-3. Tris-OTf-borazine 4 (295.5 mg, $0.277 \mathrm{mmol}), \mathrm{K}_{2} \mathrm{CO}_{3}(462.0 \mathrm{mg}, 3.328 \mathrm{mmol})$, compound 8 (341.9 mg, $1.114 \mathrm{mmol})$ and $\left[\mathrm{Pd}\left(\mathrm{PPh}_{3}\right)_{4}\right]\left(19.2 \mathrm{mg}, 16.6 \times 10^{-3} \mathrm{mmol}\right)$ were suspended in a mixture of 1,4-dioxane and water $(3: 1 \mathrm{v} / \mathrm{v})(16 \mathrm{~mL})$ (degassed with 5 freeze-pump-thaw cycles) in a flame-dried 50-mL Schlenk flask. The reaction was carried out at $105^{\circ} \mathrm{C}$ for $18 \mathrm{~h}$. The reaction mixture was cooled down to r.t., diluted with $\mathrm{CH}_{2} \mathrm{Cl}_{2}$ $(100 \mathrm{~mL})$, filtrated on celite, washed with brine $(100 \mathrm{~mL})$ and $\mathrm{H}_{2} \mathrm{O}(3 \times 100 \mathrm{~mL})$. The organic phase was dried over $\mathrm{MgSO}_{4}$. The crude was purified by column chromatography (cyclohexane/ $\mathrm{CH}_{2} \mathrm{Cl}_{2}$, from 0 to $10 \%$ ) affording the desired compound azo-borazine-3 as an orange solid (0.267 g, 83\%). Mp: 270-272 ${ }^{\circ} \mathrm{C} .{ }^{1} \mathrm{H}$ NMR $\left(\mathrm{CD}_{2} \mathrm{Cl}_{2}, 400\right.$ MHz): $\delta 2.47$ (s, 18 H), 6.80-6.84 (t, 3 H), 6.88-6.91 (t, 6 H), 6.97 (s, 6 H), 7.03-7.05 (d, 6 H), 7.46-7.55 (m, 9 H), 7.60-7.62 (d, $6 \mathrm{H}), 7.88-7.92(\mathrm{~m}, 12 \mathrm{H}) .{ }^{13} \mathrm{C}\left\{{ }^{1} \mathrm{H}\right\} \mathrm{NMR}\left(\mathrm{CDCl}_{3}, 100 \mathrm{MHz}\right): \delta 25.0,84.2,93.9,122.1,122.9$, 123.0, 123.1, 123.1, 123.6, 128.0, 129.2, 129.2, 129.3, 131.1, 131.3, 135.8. Signal for carbon atom attached to boron atom is missing due to quadrupolar relaxation. ${ }^{11} \mathrm{~B}-\mathrm{NMR}\left(\mathrm{CDCl}_{3}, 128 \mathrm{MHz}\right): \delta 35.98$ (br). FTIR (UATR) $v$ $\left(\mathrm{cm}^{-1}\right): 3039,2915,1598,1546,1490,1454,1422,1353,1305,1292,1223,1154,1072,1011,838,792$. HRMS (MALDI-ToF) m/z: [M+H] $]^{+}$Calcd for $\mathrm{C}_{78} \mathrm{H}_{67} \mathrm{~B}_{3} \mathrm{~N}_{9}{ }^{+}, 1162.5793$; Found 1162.6010 . 
Bis-OTf-borazine (9). Tris-OTf-borazine 4 (200.5 mg, $0.202 \mathrm{mmol}), \mathrm{K}_{2} \mathrm{CO}_{3}(33.6 \mathrm{mg}, 0.242 \mathrm{mmol})$, phenylboronic acid $\left(8.2 \mathrm{mg}, 67 \times 10^{-3} \mathrm{mmol}\right)$ and $\left[\mathrm{Pd}\left(\mathrm{PPh}_{3}\right)_{4}\right]\left(7.2 \mathrm{mg}, 6.06 \times 10^{-3} \mathrm{mmol}\right)$ were suspended in a mixture of 1,4-dioxane and water $(3: 1, \mathrm{v} / \mathrm{v})(12 \mathrm{~mL})$ (degassed with 5 freeze-pump-thaw cycles) in a flame-dried 50-mL Schlenk flask. The reaction was carried out at $105^{\circ} \mathrm{C}$ for $8 \mathrm{~h}$. The reaction mixture was cooled down to r.t., diluted with $\mathrm{CH}_{2} \mathrm{Cl}_{2}(100 \mathrm{~mL})$, filtered on celite, washed with brine $(100 \mathrm{~mL})$ and $\mathrm{H}_{2} \mathrm{O}(3 \mathrm{x} 100 \mathrm{~mL})$. The organic phase was dried over $\mathrm{MgSO}_{4}$, evaporated to a brownish solid and purified by column chromatography (cyclohexane $/ \mathrm{CH}_{2} \mathrm{Cl}_{2}$, from 0 to $10 \%$ ) yielding the desired compound 9 as a white solid (0.06 $\mathrm{g}, 30 \%$ ). $\mathrm{Mp}$ : 180.4-182.2 ${ }^{\circ} \mathrm{C} .{ }^{1} \mathrm{H}$ NMR $\left(\mathrm{CD}_{2} \mathrm{Cl}_{2}, 400 \mathrm{MHz}\right.$ ): $\delta 2.33(\mathrm{~s}, 18 \mathrm{H}), 6.49(\mathrm{~s}, 4 \mathrm{H}), 6.75-6.83(\mathrm{~m}, 17 \mathrm{H}), 7.21(\mathrm{t}, 1 \mathrm{H})$, $7.30(\mathrm{t}, 2 \mathrm{H}), 7.38-7.40(\mathrm{~d}, 2 \mathrm{H}) .{ }^{13} \mathrm{C}\left\{{ }^{1} \mathrm{H}\right\} \mathrm{NMR}\left(\mathrm{CDCl}_{3}, 101 \mathrm{MHz}\right): \delta 23.3,23.4,118.0,124.4,125.1,125.3$, 126.5, 126.7, 126.8, 126.9, 127.3, 127.5, 128.6, 138.0, 139.8, 140.4, 141.2, 145.1, 145.3, 149.2. ${ }^{19} \mathrm{~F} \mathrm{NMR}\left(\mathrm{CDCl}_{3}\right.$, $376 \mathrm{MHz}): \delta-72.75 .{ }^{11} \mathrm{~B} \mathrm{NMR}\left(\mathrm{CDCl}_{3}, 128 \mathrm{MHz}\right): \delta 35.2$ (br). FTIR (UATR) $v\left(\mathrm{~cm}^{-1}\right): 3040,2923,2854,1590$, 1492, 1454, 1419, 1363, 1310, 1240, 1208, 1142, 1120, 1075, 1013, 945, 908, 869, 845, 794, 749, 701, 582. HRMS (MALDI-ToF) m/z: [M+H] $]^{+}$Calcd for $\mathrm{C}_{50} \mathrm{H}_{45} \mathrm{~B}_{3} \mathrm{~N}_{3} \mathrm{~F}_{6} \mathrm{O}_{6} \mathrm{~S}_{2}{ }^{+}$, 994.2969; Found 994.3002.

1-nitro-2-(oct-1-ynyl)benzene (11). 1-bromo-2-nitrobenzene 10 (2.5 g, 12.5 mmol), 1-octyne (1.73 g, $2.4 \mathrm{~mL}, 12.5$ $\mathrm{mmol}),\left[\mathrm{Pd}\left(\mathrm{PPh}_{3}\right)_{4}\right](288 \mathrm{mg}, 0.25 \mathrm{mmol})$ and $\mathrm{CuBr}(73 \mathrm{mg}, 0.5 \mathrm{mmol})$ were dissolved in a freshly distilled and degassed with 3 freeze-pump-thaw cycles $\mathrm{Et}_{3} \mathrm{~N}(50 \mathrm{~mL})$ a flame-dried 100-mL Schlenk flask. The reaction was carried out at $90{ }^{\circ} \mathrm{C}$ under argon atmosphere for $15 \mathrm{~h}$. The reaction mixture was cooled down to r.t., diluted with $300 \mathrm{~mL}$ of $\mathrm{Et}_{2} \mathrm{O}$, washed with a saturated solution of $\mathrm{NH}_{4} \mathrm{Cl}(3 \times 100 \mathrm{~mL})$ and water $(3 \times 100 \mathrm{~mL})$, dried over $\mathrm{MgSO}_{4}$, and evaporated to a dark oil. The crude product was purified by column chromatography ( $n$-heptane/EtOAc, from 0 to 20\%) yielding the desired compound 11 as a brownish oil (2.6 g, 90\%). ${ }^{1} \mathrm{H} \mathrm{NMR}$ $\left(\mathrm{CDCl}_{3}, 500 \mathrm{MHz}\right): \delta 0.89(\mathrm{t}, 3 \mathrm{H}), 1.29-1.34(\mathrm{~m}, 4 \mathrm{H}), 1.46(\mathrm{~m}, 2 \mathrm{H}), 1.62(\mathrm{~m}, 2 \mathrm{H}), 2.45(\mathrm{t}, 2 \mathrm{H}), 7.36(\mathrm{t}, 1 \mathrm{H})$, $7.49(\mathrm{t}, 1 \mathrm{H}), 7.54(\mathrm{~d}, 1 \mathrm{H}), 7.92(\mathrm{~d}, 1 \mathrm{H}) .{ }^{13} \mathrm{C}\left\{{ }^{1} \mathrm{H}\right\} \mathrm{NMR}\left(\mathrm{CDCl}_{3}, 126 \mathrm{MHz}\right): \delta 14.1,19.9,22.6,28.4,28.6,31.4$, 76.0, 99.5, 119.4, 124.4, 127.9, 132.6, 134.8, 150.1. FTIR (UATR) $v\left(\mathrm{~cm}^{-1}\right): 2954,2929,2858,2228,1608,1568$, 1524, 1480, 1466, 1439, 1429, 1262, 851, 783, 744, 655. LRMS (EI-ToF) m/z: [M] Calcd for $\mathrm{C}_{14} \mathrm{H}_{17} \mathrm{NO}_{2}^{+}$, 231.1259; Found 231.131. Characterization is in accordance with data reported in the literature. ${ }^{40}$

2-octylaniline (12). 1-nitro-2-(oct-1-ynyl)-benzene 11 (2.24 g, $9.7 \mathrm{mmol})$ and $\mathrm{Pd} / \mathrm{C}(10 \%)(222.4 \mathrm{mg}, 0.204$ mmol) were suspended in EtOH $(80 \mathrm{~mL})$. The reaction mixture was hydrogenated with $\mathrm{H}_{2}(1$ atm) at r.t. for $6 \mathrm{~h}$. The crude was filtrated on celite and evaporated to brown oil (1.9 g, 95\%). ${ }^{1} \mathrm{H}$ NMR (CDCl, $\left.500 \mathrm{MHz}\right): \delta 0.92$ (t, 3 H), 1.31-1.43 (m, 10 H), 1.64 (m, 2 H), 2.49 (t, 2 H), 3.62 (s, 2 H), 6.68-6.70 (d, 1 H), 6.76 (t, 1 H), 7.03-7.07 (m, $2 \mathrm{H}) .{ }^{13} \mathrm{C}\left\{{ }^{1} \mathrm{H}\right\} \operatorname{NMR}\left(\mathrm{CDCl}_{3}, 100 \mathrm{MHz}\right): \delta 14.2,22.7,28.8,29.4,29.6,29.8,31.4,32.0,115.6,118.7,126.8$, 127.0, 129.4, 144.1. FTIR (UATR) $v\left(\mathrm{~cm}^{-1}\right):$ 3468, 3379, 3022, 2954, 2853, 1619, 1583, 1526, $1456,1272,1156$. LRMS (ESI-ToF) m/z: [M] $]^{+}$Calcd for $\mathrm{C}_{14} \mathrm{H}_{23} \mathrm{~N}^{+}$, 205.1825; Found 205.1083. Characterization is in accordance with data reported in the literature. ${ }^{40}$

4-bromo-2-octylaniline (13). A solution of pyridinium hydrobromide perbromide (2.33 g, $7.3 \mathrm{mmol})$ in THF (50 $\mathrm{mL}$ ) was added dropwise over $50 \mathrm{~min}$ to 2-octylaniline 12 (1.50 g, $7.3 \mathrm{mmol})$ in THF (50 mL). After completion of the addition, the solution was stirred at r.t. for $1 \mathrm{~h}$. The solution was filtered to remove the formed pyridinium hydrobromide salt. Then, the solution was treated with a saturated solution of $\mathrm{NaHCO}_{3}(3 \mathrm{x} 100 \mathrm{ml})$ to remove any excess of bromide, washed with water $(3 \times 100 \mathrm{~mL})$, dried over $\mathrm{MgSO}_{4}$ and evaporated to a dark oil. The 
crude product was purified by column chromatography ( $n$-heptane/EtOAc, from 0 to 30\%) yielding the desired compound 13 as a brownish oil $(1.47 \mathrm{~g}, 71 \%) .{ }^{1} \mathrm{H}$ NMR $\left(\mathrm{CDCl}_{3}, 500 \mathrm{MHz}\right): \delta 0.91(\mathrm{t}, 3 \mathrm{H}), 1.30-1.42(\mathrm{~m}, 10 \mathrm{H})$, 1.60 (m, $2 \mathrm{H}), 2.43$ (t, $2 \mathrm{H}), 3.61(\mathrm{~s}, 2 \mathrm{H}), 6.53$ (d, $1 \mathrm{H}), 7.11-7.12(\mathrm{dd}, 1 \mathrm{H}), 7.15(\mathrm{~d}, 1 \mathrm{H}) .{ }^{13} \mathrm{C}\left\{{ }^{1} \mathrm{H}\right\} \mathrm{NMR}\left(\mathrm{CDCl}{ }_{3}\right.$, $100 \mathrm{MHz}): \delta 13.2,21.8,27.5,28.3,28.6,28.7,30.2,31.0,109.4,116.0,128.2,128.5,130.9,142.2$. FTIR (UATR) $v\left(\mathrm{~cm}^{-1}\right): 3475,3387,2953,2853,1619,1488,1409,1278,1077 . \mathrm{MS}(\mathrm{GC}-\mathrm{MS}) \mathrm{m} / \mathrm{z}:[\mathrm{M}]^{+} \mathrm{Calcd}$ for $\mathrm{C}_{14} \mathrm{H}_{22} \mathrm{BrN}^{+}$, 283.0936; Found 283.12. Characterization is in accordance with data reported in the literature. ${ }^{40}$

2-octyl-4-(4,4,5,5-tetramethyl-1,3,2-dioxaborolan-2-yl)aniline (14). 4-bromo-2-octylaniline 13 (1.32 g, 4.62 mmol), $\mathrm{B}_{2} \mathrm{Pin}_{2}(1.41 \mathrm{~g}, 5.54 \mathrm{mmol}), \mathrm{KOAc}(1.36 \mathrm{~g}, 13.86 \mathrm{mmol})$ and $\left[\mathrm{Pd}(\mathrm{dppf}) \mathrm{Cl}_{2} \cdot \mathrm{CH}_{2} \mathrm{Cl}_{2}\right](100 \mathrm{mg}, 0.14 \mathrm{mmol})$ were suspended in 1,4-dioxane (degassed by 3 freeze-to-thaw cycles) (45 mL). The reaction was carried out at 85 ${ }^{\circ} \mathrm{C}$ for $16 \mathrm{~h}$. After cooling down to r.t. the reaction mixture was diluted with EtOAc $(100 \mathrm{~mL})$, filtered over celite, washed with brine $(2 \times 100 \mathrm{~mL})$ and $\mathrm{H}_{2} \mathrm{O}(3 \times 100 \mathrm{~mL})$, dried over $\mathrm{MgSO}_{4}$ and evaporated to black oil. The crude product was purified by column chromatography (EtOAc/n-heptane, from 0 to $20 \%$ ) yielding the molecule 14 as a brownish oil $(0.765 \mathrm{~g}, 50 \%) .{ }^{1} \mathrm{H} \mathrm{NMR}\left(\mathrm{CDCl}_{3}, 500 \mathrm{MHz}\right): \delta 0.88(\mathrm{t}, 3 \mathrm{H}), 1.26-1.32(\mathrm{~m}, 22 \mathrm{H})($ integration $34 \mathrm{H}$ is due to the presence of pinacolborane $12 \mathrm{H}), 1.61(\mathrm{~m}, 2 \mathrm{H}), 2.49(\mathrm{t}, 2 \mathrm{H}), 3.81(\mathrm{~s}, 2 \mathrm{H}), 6.64-6.66(\mathrm{~d}, 1 \mathrm{H}), 7.49$ (m, $2 \mathrm{H}) .{ }^{13} \mathrm{C}\left\{{ }^{1} \mathrm{H}\right\} \mathrm{NMR}\left(\mathrm{CDCl}_{3}, 101 \mathrm{MHz}\right): \delta 14.2,22.8,25.1,29.0,29.4,29.6,30.0,31.5,32.0,77.0,77.6,77,7$, 83.3, 83.6, 114.7, 125.8, 134.2, 136.5, 147.4. ${ }^{11} \mathrm{~B} \mathrm{NMR}\left(\mathrm{CDCl}_{3}, 128 \mathrm{MHz}\right): \delta 29.4$ (s). FTIR (UATR) $v\left(\mathrm{~cm}^{-1}\right)$ : 3473, 3365, 2925, 1621, 1605, 1418, 1353, 1325, 1303, 1165, 1123, 1106, 1090, 964, 856. HRMS (ESI-ToF) m/z: $[\mathrm{M}+\mathrm{H}]^{+}$Calcd for $\mathrm{C}_{20} \mathrm{H}_{34} \mathrm{BNO}_{2}{ }^{+}, 332.2755$; Found 332.2760. Characterization is in accordance with data reported in the literature. ${ }^{40}$

3-Hexyl-2,5-diiodothiophene (16). A solution of $\mathrm{N}$-Iodosuccinimide (NIS) (14.04 g, $62.4 \mathrm{mmol})$ in $\mathrm{CHCl}_{3}$ (30 $\mathrm{mL})$ was added dropwise to a solution of 3-hexylthiophene $15(5.3 \mathrm{~mL}, 29.71 \mathrm{mmol})$ in a mixture of acetic acid and $\mathrm{CHCl}_{3}(30: 10 \mathrm{~mL})$. The reaction mixture was stirred in dark at r.t. for $24 \mathrm{~h}$. The reaction mixture was diluted with $\mathrm{CH}_{2} \mathrm{Cl}_{2}(100 \mathrm{~mL})$, quenched with a saturated solution of $\mathrm{Na}_{2} \mathrm{~S}_{2} \mathrm{O}_{3}(50 \mathrm{~mL})$, washed with $\mathrm{H}_{2} \mathrm{O}(3 \mathrm{x} 100 \mathrm{~mL})$, dried over $\mathrm{MgSO}_{4}$ and evaporated to light pink oil. The crude product was purified by column chromatography (cyclohexane) affording the desired compound 16 as a colorless oil (11.2 g, 90\%). ${ }^{1} \mathrm{H} \mathrm{NMR}\left(\mathrm{CDCl}_{3}, 400 \mathrm{MHz}\right): \delta$ $0.92(\mathrm{t}, 3 \mathrm{H}), 1.32(\mathrm{~m}, 6 \mathrm{H}), 1.55(\mathrm{~m}, 2 \mathrm{H}), 2.50(\mathrm{t}, 2 \mathrm{H}), 6.90(\mathrm{~s}, 1 \mathrm{H}) .{ }^{13} \mathrm{C}\left\{{ }^{1} \mathrm{H}\right\} \mathrm{NMR}\left(\mathrm{CDCl}_{3}, 101 \mathrm{MHz}\right): \delta 14.3$, 22.7, 28.9, 30.0, 31.7, 32.1, 76.1, 77.2, 137.8, 149.5. FTIR (UATR) $v\left(\mathrm{~cm}^{-1}\right): 2953,2923,2853,1525,1464,1395$, 1190, 982, 907, 827, 724, 695, 649, 468. HRMS (ESI-ToF) m/z: [M+H] $]^{+}$Calcd for $\mathrm{C}_{10} \mathrm{H}_{15} \mathrm{I}_{2} \mathrm{~S}^{+}$, 420.8978; Found 420.8961. Characterization is in accordance with data reported in the literature. ${ }^{40}$

(4,4'-(3-hexylthiophene-2,5-diyl)bis(2-octylaniline) 2-octyl-4-(4,4,5,5-tetramethyl-1,3,2-dioxaborolan-2-yl)aniline $\quad 14 \quad(520.1 \quad \mathrm{mg}, \quad 1.6 \quad \mathrm{mmol})$, 3-hexyl-2,5-diiodothiophene $16(300.2 \mathrm{mg}, 0.71 \mathrm{mmol})$ and $\mathrm{K}_{2} \mathrm{CO}_{3}(790 \mathrm{mg}, 5.72 \mathrm{mmol})$ were dissolved in a mixture of 1,4-dioxane and $\mathrm{H}_{2} \mathrm{O}(9: 3 \mathrm{v} / \mathrm{v})(12 \mathrm{~mL})$. The reaction mixture was degassed by three freeze-pump-thaw cycles. Then, $\left[\mathrm{Pd}\left(\mathrm{PPh}_{3}\right)_{4}\right](46.2 \mathrm{mg}, 0.04 \mathrm{mmol})$ was added. The reaction was carried out at $105{ }^{\circ} \mathrm{C}$ for $24 \mathrm{~h}$. The mixture was cooled down to r.t., diluted with $\mathrm{CH}_{2} \mathrm{Cl}_{2}(50 \mathrm{~mL})$, filtered over celite, washed with brine $(2 \mathrm{x} 100$ $\mathrm{mL}$ ) and water (2 x $100 \mathrm{~mL})$, dried over $\mathrm{MgSO}_{4}$, evaporated and purified by column chromatography (cyclohexane/EtOAc, from 0 to $10 \%$ ) yielding the desired compound $\mathbf{1 7}$ as yellow viscous oil $(0.122 \mathrm{~g}, 30 \%)$. ${ }^{1} \mathrm{H}$ NMR $\left(\mathrm{CDCl}_{3}, 400 \mathrm{MHz}\right): \delta 0.89-0.90(\mathrm{t}, 9 \mathrm{H}), 1.30-1.45(\mathrm{~m}, 24 \mathrm{H}), 1.66(\mathrm{~m}, 6 \mathrm{H}), 2.52(\mathrm{t}, 4 \mathrm{H}), 2.63(\mathrm{t}, 2 \mathrm{H}), 3.70$ 

22.8, 22.8, 28.8, 28.9, 29.2, 29.4, 29.5, 29.7, 29.7, 29.8, 29.9, 31.2, 31.4, 31.5, 31.9, 32.0, 115.5, 115.9, 123.8, 124.4, 125.4, 125.8, 126.9, 127.0, 127.3, 127.8, 130.4, 136.5, 138.4, 141.9, 143.4, 143.6. FTIR (UATR) $v\left(\mathrm{~cm}^{-1}\right)$ : 3380, 2954, 2923, 2853, 1619, 1497, 1464, 1377, 1283, 1156, 907, 816, 732, 646, 532. LRMS (ESI-ToF) m/z: $[\mathrm{M}+\mathrm{H}]^{+}$Calcd for $\mathrm{C}_{38} \mathrm{H}_{59} \mathrm{~N}_{2} \mathrm{~S}^{+}, 575.4393$; Found 575.4331. Characterization is in accordance with data reported in the literature. ${ }^{40}$

1-bromo-4-nitrosobenzene (19). A solution of Oxone ${ }^{\circledR}(7.2 \mathrm{~g}, 11.7 \mathrm{mmol})$ in water $(48 \mathrm{~mL})$ was added to a solution of freshly recrystallized 4-bromoaniline $(1.04 \mathrm{~g}, 5.84 \mathrm{mmol})$ in $\mathrm{CH}_{2} \mathrm{Cl}_{2}(12 \mathrm{~mL})$. The mixture was stirred at r.t. for $4 \mathrm{~h}$. The reaction mixture was extracted with $\mathrm{CH}_{2} \mathrm{Cl}_{2}(3 \times 20 \mathrm{~mL})$ to give the desired compound 19 as a pale green solid that was used in the next step without further purification $\left(2.15 \mathrm{~g}\right.$, quant.). ${ }^{1} \mathrm{H} \mathrm{NMR}\left(\mathrm{CDCl}_{3}, 400\right.$ $\mathrm{MHz}): \delta 7.78(\mathrm{~s}, 4 \mathrm{H})$.

\section{(1E,1'E)-2,2'-((3-hexylthiophene-2,5-diyl)bis(2-octyl-4,1-phenylene))bis(1-(4-bromophenyl)diazene)} l-bromo-4-nitrosobenzene 19 (2.14 g, $11.51 \mathrm{mmol})$ and compound 17 (1.51 g, $2.63 \mathrm{mmol})$ were dissolved in a mixture of $\mathrm{AcOH}$ and EtOAc $(1: 1 \mathrm{v} / \mathrm{v})(40 \mathrm{~mL})$. The reaction mixture was stirred at $45{ }^{\circ} \mathrm{C}$ for $36 \mathrm{~h}$. The mixture was cooled down to r.t., diluted with $\mathrm{CH}_{2} \mathrm{Cl}_{2}(50 \mathrm{~mL})$, washed with water $(3 \times 100 \mathrm{~mL})$, dried over $\mathrm{MgSO}_{4}$, evaporated and purified by column chromatography (cyclohexane/ $\mathrm{CH}_{2} \mathrm{Cl}_{2}$, from 0 to $30 \%$ ) yielding the desired compound 20 as a viscous orange oil (1.08 g, 45\%). ${ }^{1} \mathrm{H}$ NMR $\left(\mathrm{CDCl}_{3}, 500 \mathrm{MHz}\right): \delta 0.87(\mathrm{t}, 9 \mathrm{H}), 1.25-1.42(\mathrm{~m}, 26$ H), 1.71 (m, 6 H), 2.75 (t, 2 H), 3.14-3.19 (q, 4 H), 7.34 (s, 1 H), 7.39-7.41 (dd, 1 H), 7.48 (d, 1 H), $7.52-7.54$ (dd, $1 \mathrm{H}), 7.60(\mathrm{~d}, 1 \mathrm{H}), 7.65-7.67(\mathrm{~m}, 4 \mathrm{H}), 7.72-7.75(\mathrm{~d}, 2 \mathrm{H}), 7.79-7.82(\mathrm{~m}, 4 \mathrm{H}) .{ }^{13} \mathrm{C}\left\{{ }^{1} \mathrm{H}\right\} \mathrm{NMR}\left(\mathrm{CDCl}_{3}, 126 \mathrm{MHz}\right)$ : $\delta 14.2,14.3,22.8,22.8,29.4,29.4,29.6,29.6,29.7,31.2,31.6,31.8,31.8,32.0,32.3,32.4,115.8,116.2,123.8$, $124.5,124.6,125.2,125.3,127.1,127.3,127.4,131.1,132.5,132.5,137.1,137.7,138.1,141.1,142.1,143.8$, 144.4, 149.2, 149.3, 151.9, 152.0. FTIR (UATR) $v\left(\mathrm{~cm}^{-1}\right): 2953,2922,2853,1905,1596,1574,1476.67,1453$, $1411,1377,1297,1260,1222,1185,1149,1117,1066,1007,886,832,722,704$. HRMS (ESI-ToF) m/z: [M+H] ${ }^{+}$ Calcd for $\mathrm{C}_{50} \mathrm{H}_{63} \mathrm{Br}_{2} \mathrm{~N}_{4} \mathrm{~S}^{+}$, 909.3135; Found 909.3126.

(1E,1'E)-2,2'-((3-hexylthiophene-2,5-diyl)bis(2-octyl-4,1-phenylene))bis(1-(4-(4,4,5,5-tetramethyl-1,3,2-dioxabor olan-2-yl)phenyl)diazene) (AB-3HT-(BPin) $)$ (21). Compound 20 (1.00 g, $1.1 \mathrm{mmol}), \mathrm{B}_{2} \operatorname{Pin}_{2}(1.12 \mathrm{~g}, 4.41 \mathrm{mmol})$, KOAc $(0.6477 \mathrm{~g}, 6.6 \mathrm{mmol})$ and $\left[\mathrm{Pd}(\mathrm{dppf}) \mathrm{Cl}_{2} \cdot \mathrm{CH}_{2} \mathrm{Cl}_{2}\right](54 \mathrm{mg}, 0.066 \mathrm{mmol})$ were suspended in 1,4-dioxane (degassed by 3 freeze-to-thaw cycles) $(45 \mathrm{~mL})$. The reaction was carried out at $90^{\circ} \mathrm{C}$ for $24 \mathrm{~h}$. After cooling down to r.t. the reaction mixture was diluted with $\mathrm{CH}_{2} \mathrm{Cl}_{2}(100 \mathrm{~mL})$, filtered over celite to remove the Pd catalyst, washed with brine $(2 \times 100 \mathrm{~mL})$ and $\mathrm{H}_{2} \mathrm{O}(3 \times 100 \mathrm{~mL})$, dried over $\mathrm{MgSO}_{4}$ and evaporated to a black oil purified by column chromatography (cyclohexane $/ \mathrm{CH}_{2} \mathrm{Cl}_{2}$, from 0 to $10 \%$ ) to yield the desired compound 21 as orange viscous oil (0.72 g, 65\%). ${ }^{1} \mathrm{H}$ NMR $\left(\mathrm{CDCl}_{3}, 400 \mathrm{MHz}\right): \delta 0.87(\mathrm{t}, 9 \mathrm{H}), 1.27-1.38(\mathrm{~m}, 50 \mathrm{H}), 1.73(\mathrm{~m}, 6 \mathrm{H}), 2.75$ $(\mathrm{t}, 2 \mathrm{H}), 3.18(\mathrm{q}, 4 \mathrm{H}), 7.34(\mathrm{~s}, 1 \mathrm{H}), 7.40-7.42(\mathrm{dd}, 1 \mathrm{H}), 7.49$ (d, $1 \mathrm{H}), 7.53-7.55(\mathrm{dd}, 1 \mathrm{H}), 7.61(\mathrm{~d}, 1 \mathrm{H})$, 7.73-7.76 (m, $2 \mathrm{H}), 7.89-7.92(\mathrm{~m}, 4 \mathrm{H}), 7.96-7.99(\mathrm{~m}, 4 \mathrm{H}) .{ }^{13} \mathrm{C}\left\{{ }^{1} \mathrm{H}\right\} \mathrm{NMR}\left(\mathrm{CDCl}_{3}, 100 \mathrm{MHz}\right): \delta 14.2,14.2,22.8$, 22.8, 25.0, 25.2, 27.0, 27.1, 29.4, 29.4, 29.4, 29.6, 29.6, 29.7, 29.7, 30.3, 31.2, 31.8, 32.0, 32.3, 32.4, 43.6, 83.6, 84.2, 84.2, 115.8, 116.1, 122.2, 123.7, 127.0, 127.3, 127.3, 131.1, 135.8, 135.8, 137.0, 137.6, 138.1, 141.0, 142.1, $143.7,144.4,149.5,149.6,155.0,155.1$. Signals for the two carbon atoms attached to boron atoms are missing due to quadrupolar relaxation. ${ }^{11} \mathrm{~B} \mathrm{NMR}\left(\mathrm{CDCl}_{3}, 128 \mathrm{MHz}\right): \delta 29.3$ (s). FTIR (UATR) $v\left(\mathrm{~cm}^{-1}\right): 2923,2853$, 
$1599,1571,1501,1480,1456,1396,1355,1324,1272,1216,1186,1124,1142,1086,1014,962,886,858,848$, 830, 736, 668, 653, 578, 540. HRMS (ESI-ToF) m/z: $[\mathrm{M}+\mathrm{H}]^{+}$Calcd for $\mathrm{C}_{62} \mathrm{H}_{87} \mathrm{~B}_{2} \mathrm{~N}_{4} \mathrm{O}_{4} \mathrm{~S}^{+}$, 1005.6668; Found 1005.6706 .

P(AB-3HT-borazine) polymer. Bis-OTf-borazine 9 (100.00 mg, $0.1 \mathrm{mmol}$ ), compound 21 (101.06 mg, $0.1 \mathrm{mmol}$ ), $\mathrm{K}_{2} \mathrm{CO}_{3}(1.66 \mathrm{~g}, 1.2 \mathrm{mmol})$ were suspended in a mixture of toluene and water $(2: 0.2 \mathrm{v} / \mathrm{v})$. The reaction mixture was degassed by three freeze-pump-thaw cycles. Then, $\left[\mathrm{Pd}\left(\mathrm{PPh}_{3}\right)_{4}\right](17.33 \mathrm{mg}, 0.015 \mathrm{mmol})$ was added. The reaction was vigorously stirred at $100{ }^{\circ} \mathrm{C}$ for $48 \mathrm{~h}$. The deep-orange reaction mixture turned gradually into brown accompanied with the precipitation of a black solid. P(AB-3HT-borazine) polymer was obtained by purification via Soxhlet extraction for $12 \mathrm{~h}$ using $\mathrm{CHCl}_{3}$ followed by precipitation in $\mathrm{MeOH}$. The orange-like polymer was finally dried under reduced pressure at $50{ }^{\circ} \mathrm{C}$ for 24 hours in $60 \%$ yield. Size exclusion chromatography (SEC) relative to polystyrene standard in THF $\left(+2 \% \mathrm{Et}_{3} \mathrm{~N}\right)$ at $30^{\circ} \mathrm{C}: \mathrm{M}_{\mathrm{n}}=13.2 \mathrm{kDa}, \mathrm{M}_{\mathrm{w}}=25.0 \mathrm{kDa}, \mathrm{Ð}_{\mathrm{M}}=1.92, \mathrm{DP}=9$. ${ }^{1} \mathrm{H} \mathrm{NMR}\left(\mathrm{CDCl}_{3}, 500 \mathrm{MHz}\right): \delta 0.86$ (br, $\left.9 \mathrm{H}\right), 1.25-1.40$ (br, $\left.50 \mathrm{H}\right), 1.71$ (s, $\left.6 \mathrm{H}\right), 2.17$ (s, $\left.6 \mathrm{H}\right), 2.41-2.43$ (br, 12 H), 2.74 (s, 2 H), 3.17 (s, 4 H), 6.75 (s, 1 H), 6.82 (s, 4 H), 6.92 (s, 15 H), 7.22 (s, 1 H), 7.31 (br, 4 H), 7.41 (s, 2 H), 7.47 (s, $1 \mathrm{H}), 7.58$ (br, $6 \mathrm{H}), 7.72$ (br, $2 \mathrm{H}), 7.89$ (s, $4 \mathrm{H})$. 


\section{ASSOCIATED CONTENT}

\section{Supporting Information}

Synthetic schemes, copies of NMR spectra and thermal characterization data. This material is available free of charge via the Internet at http://pubs.acs.org.

CCDC 1906843, 1906842 and 1906844 contain the supplementary crystallographic data for compounds $\mathbf{3}$, Azo-borazine-3 and 4. These data can be obtained free of charge from The Cambridge Crystallographic Data Centre via https://www.ccdc.cam.ac.uk/structures.

\section{AUTHOR INFORMATION}

\section{Corresponding Author}

bonifazid@cardiff.ac.uk

$\underline{\text { olivier.coulembier@,umons.ac.be }}$

\section{ORCID}

Hamid Oubaha: 0000-0001-9609-7094

Nicola Demitri: 0000-0003-0288-3233

Notes

The authors declare no competing financial interest.

\section{ACKNOWLEDGEMENT}

The authors thank the Universities of Namur and Mons for the financial support to H.O. doctoral fellowship. D.B. thanks the Walloon Region for the 'Flycoat' and 'TUBOLED' POC projects, the Science Policy Office of the Belgian Federal Government (BELSPO-IAP 7/05 project) and School of Chemistry at Cardiff University. O.C. is Research Associate for the F.R.S. -FNRS.

\section{REFERENCES}

1. (a) Nguyen, T.-T.-T.; Türp, D.; Wang, D.; Nölscher, B.; Laquai, F.; Müllen, K., A Fluorescent, Shape-Persistent Dendritic Host with Photoswitchable Guest Encapsulation and Intramolecular Energy Transfer. J. Am. Chem. Soc. 2011, 133, 11194-11204; (b) Russew, M.-M.; Hecht, S., Photoswitches: From Molecules to Materials. Adv. Mater. 2010, 22, 3348-3360; (c) Shinkai, S.; Nakaji, T.; Ogawa, T.; Shigematsu, K.; Manabe, O., Photoresponsive crown ethers. 2. Photocontrol of ion extraction and ion transport by a bis(crown ether) with a butterfly-like motion. $J$. Am. Chem. Soc. 1981, 103, 111-115.

2. (a) García-Amorós, J.; Velasco, D., Recent advances towards azobenzene-based light-driven real-time information-transmitting materials. Beilstein J. Org. Chem 2012, 8, 1003-1017; (b) Bandara, H. M. D.; Burdette, S. C., Photoisomerization in different classes of azobenzene. Chem. Soc. Rev. 2012, 41, 1809-1825; (c) Qu, D.-H.; Wang, Q.-C.; Zhang, Q.-W.; Ma, X.; Tian, H., Photoresponsive Host-Guest Functional Systems. Chem. Rev. 2015, 115, 7543-7588; (d) Hartley, G. S., The Cis-form of Azobenzene. Nature 1937, 140, 281-281; (e) Moreno, J.; Gerecke, M.; 
Grubert, L.; Kovalenko, S. A.; Hecht, S., Sensitized Two-NIR-Photon Z $\rightarrow$ E Isomerization of a Visible-Light-Addressable Bistable Azobenzene Derivative. Angew. Chem. Int. Ed. 2016, 55, 1544-1547; (f) Zeitouny, J.; Aurisicchio, C.; Bonifazi, D.; De Zorzi, R.; Geremia, S.; Bonini, M.; Palma, C.-A.; Samorì, P.; Listorti, A.; Belbakra, A.; Armaroli, N., Photoinduced structural modifications in multicomponent architectures containing azobenzene moieties as photoswitchable cores. J. Mater. Chem. 2009, 19, 4715-4724.

3. (a) Liaros, N.; Couris, S.; Maggini, L.; De Leo, F.; Cattaruzza, F.; Aurisicchio, C.; Bonifazi, D., NLO Response of Photoswitchable Azobenzene-Based Materials. ChemPhysChem 2013, 14, 2961-2972; (b) Maggini, L.; Marangoni, T.; Georges, B.; Malicka, J. M.; Yoosaf, K.; Minoia, A.; Lazzaroni, R.; Armaroli, N.; Bonifazi, D., Azobenzene-based supramolecular polymers for processing MWCNTs. Nanoscale 2013, 5, 634-645; (c) Weber, C.; Liebig, T.; Gensler, M.; Zykov, A.; Pithan, L.; Rabe, J. P.; Hecht, S.; Bléger, D.; Kowarik, S., Cooperative Switching in Nanofibers of Azobenzene Oligomers. Sci. Rep. 2016, 6, 25605; (d) Bléger, D.; Ciesielski, A.; Samorì, P.; Hecht, S., Photoswitching Vertically Oriented Azobenzene Self-Assembled Monolayers at the Solid-Liquid Interface. Chem. Eur. J. 2010, 16, 14256-14260; (e) Döbbelin, M.; Ciesielski, A.; Haar, S.; Osella, S.; Bruna, M.; Minoia, A.; Grisanti, L.; Mosciatti, T.; Richard, F.; Prasetyanto, E. A.; De Cola, L.; Palermo, V.; Mazzaro, R.; Morandi, V.; Lazzaroni, R.; Ferrari, A. C.; Beljonne, D.; Samorì, P., Light-enhanced liquid-phase exfoliation and current photoswitching in graphene-azobenzene composites. Nat. Commun. 2016, 7, 11090; (f) Castellanos, S.; Goulet-Hanssens, A.; Zhao, F.; Dikhtiarenko, A.; Pustovarenko, A.; Hecht, S.; Gascon, J.; Kapteijn, F.; Bléger, D., Structural Effects in Visible-Light-Responsive Metal-Organic Frameworks Incorporating ortho-Fluoroazobenzenes. Chem. Eur. J. 2016, 22, 746-752; (g) Mahesh, S.; Gopal, A.; Thirumalai, R.; Ajayaghosh, A., Light-Induced Ostwald Ripening of Organic Nanodots to Rods. J. Am. Chem. Soc. 2012, 134, 7227-7230.

4. (a) Velema, W. A.; Szymanski, W.; Feringa, B. L., Photopharmacology: Beyond Proof of Principle. J. Am. Chem. Soc. 2014, 136, 2178-2191; (b) Broichhagen, J.; Frank, J. A.; Trauner, D., A Roadmap to Success in Photopharmacology. Acc. Chem. Res. 2015, 48, 1947-1960; (c) Woolley, G. A., Photocontrolling Peptide $\alpha$ Helices. Acc. Chem. Res. 2005, 38, 486-493; (d) Schütt, M.; Krupka, S. S.; Milbradt, A. G.; Deindl, S.; Sinner, E.-K.; Oesterhelt, D.; Renner, C.; Moroder, L., Photocontrol of Cell Adhesion Processes: Model Studies with Cyclic Azobenzene-RGD Peptides. Chem. Biol. 2003, 10, 487-490; (e) Stein, M.; Middendorp, S. J.; Carta, V.; Pejo, E.; Raines, D. E.; Forman, S. A.; Sigel, E.; Trauner, D., Azo-Propofols: Photochromic Potentiators of GABAA Receptors. Angew. Chem. Int. Ed. 2012, 51, 10500-10504; (f) Aemissegger, A.; Kräutler, V.; van Gunsteren, W. F.; Hilvert, D., A Photoinducible B-Hairpin. J. Am. Chem. Soc. 2005, 127, 2929-2936.

5. (a) Engel, S.; Möller, N.; Ravoo, B. J., Stimulus-Responsive Assembly of Nanoparticles using Host-Guest Interactions of Cyclodextrins. Chem. Eur. J. 2018, 24, 4741-4748; (b) Tomatsu, I.; Hashidzume, A.; Harada, A., Photoresponsive Hydrogel System Using Molecular Recognition of a-Cyclodextrin. Macromolecules 2005, 38, 5223-5227; (c) Yamaguchi, H.; Kobayashi, Y.; Kobayashi, R.; Takashima, Y.; Hashidzume, A.; Harada, A., Photoswitchable gel assembly based on molecular recognition. Nat. Commun. 2012, 3, 603; (d) Goswami, S.; Ghosh, K.; Halder, M., Molecular recognition: Hydrogen bonding induced configurational locking of a new photoresponsive receptor by dicarboxylic acids. Tetrahedron Lett. 1999, 40, 1735-1738; (e) Goodman, A.; Breinlinger, E.; Ober, M.; Rotello, V. M., Controlled Multi-Stage Recognition of Guests Using Orthogonal Electro- and Photochemical Inputs. J. Am. Chem. Soc. 2001, 123, 6213-6214; (f) Dabrowa K.; Niedbała, P.; Jurczak, J., Anion-tunable control of thermal Z-E isomerisation in basic azobenzene receptors. Chem. Commun., 2014, 50, 15748-15751; (g) Lohse, M.; Nowosinski, K.; Traulsen, N. L.; Achazi, A. J.; von Krbek, L. K. S.; Paulus, B.; Schalley, C. A.; Hecht, S., Gating the photochromism of an azobenzene by strong host-guest interactions in a divalent pseudo[2]rotaxane. Chem. Commun. 2015, 51, 9777-9780; 
7. (a) Stock, A.; Pohland, E., Borwasserstoffe, VIII. Zur Kenntnis des $\mathrm{B}_{2} \mathrm{H}_{6}$ und des $\mathrm{B}_{5} \mathrm{H}_{11}$. Ber. Dtsch. Chem. Ges. 1926, 59, 2210-2215; (b) Wiberg, E.; Bolz, A., Das “norganische Benzol” $\mathrm{B}_{3} \mathrm{~N}_{3} \mathrm{H}_{6}$. Ber. Dtsch. Chem. Ges. 1940, 73, 209-232; (c) Kiran, B.; Phukan, A. K.; Jemmis, E. D., Is Borazine Aromatic? Unusual Parallel Behavior between Hydrocarbons and Corresponding B-N Analogues. Inorg. Chem. 2001, 40, 3615-3618; (d) Bonifazi, D.; Fasano, F.; Lorenzo-Garcia, M. M.; Marinelli, D.; Oubaha, H.; Tasseroul, J., Boron-nitrogen doped carbon scaffolding: organic chemistry, self-assembly and materials applications of borazine and its derivatives. Chem. Commun. 2015, 51, 15222-15236.

8. Kervyn, S.; Fenwick, O.; Di Stasio, F.; Shin, Y. S.; Wouters, J.; Accorsi, G.; Osella, S.; Beljonne, D.; Cacialli, F.; Bonifazi, D., Polymorphism, Fluorescence, and Optoelectronic Properties of a Borazine Derivative. Chem. Eur. J. 2013, 19, 7771-7779.

9. (a) Schwarz, M.; Garnica, M.; Fasano, F.; Demitri, N.; Bonifazi, D.; Auwärter, W., BN-Patterning of Metallic Substrates through Metal Coordination of Decoupled Borazines. Chem. Eur. J. 2018, 24, 9565-9571; (b) Auwärter, W., Hexagonal boron nitride monolayers on metal supports: Versatile templates for atoms, molecules and nanostructures. Surf. Sci. Rep. 2018.

10. (a) Marinelli, D.; Fasano, F.; Najjari, B.; Demitri, N.; Bonifazi, D., Borazino-Doped Polyphenylenes. J. Am. Chem. Soc. 2017, 139, 5503-5519; (b) Dosso, J.; Marinelli, D.; Demitri, N.; Bonifazi, D., Structural Properties of Highly Doped Borazino Polyphenylenes Obtained through Condensation Reaction. ACS Omega 2019, 4, 9343-9351.

11. Dosso, J.; Tasseroul, J.; Fasano, F.; Marinelli, D.; Biot, N.; Fermi, A.; Bonifazi, D., Synthesis and Optoelectronic Properties of Hexa-peri-hexabenzoborazinocoronene. Angew. Chem. Int. Ed. 2017, 56, $4483-4487$.

12. (a) Riensch, N. A.; Deniz, A.; Kühl, S.; Müller, L.; Adams, A.; Pich, A.; Helten, H., Borazine-based inorganic-organic hybrid cyclomatrix microspheres by silicon/boron exchange precipitation polycondensation. Polym. Chem. 2017, 8, 5264-5268; (b) Reich, T. E.; Jackson, K. T.; Li, S.; Jena, P.; El-Kaderi, H. M., Synthesis and characterization of highly porous borazine-linked polymers and their performance in hydrogen storage application. $J$. Mater. Chem. 2011, 21, 10629-10632; (c) Reich, T. E.; Behera, S.; Jackson, K. T.; Jena, P.; El-Kaderi, H. M., Highly 
selective $\mathrm{CO}_{2} / \mathrm{CH}_{4}$ gas uptake by a halogen-decorated borazine-linked polymer. J. Mater. Chem. 2012, 22, 13524-13528.

13. (a) Wang, X.-Y.; Zhuang, F.-D.; Wang, R.-B.; Wang, X.-C.; Cao, X.-Y.; Wang, J.-Y.; Pei, J., A Straightforward Strategy toward Large BN-Embedded $\pi$-Systems: Synthesis, Structure, and Optoelectronic Properties of Extended BN Heterosuperbenzenes. J. Am. Chem. Soc. 2014, 136, 3764-3767; (b) Yang, D.-T.; Shi, Y.; Peng, T.; Wang, S., BN-Heterocycles Bearing Two BN Units: Influence of the Linker and the Location of BN Units on Electronic Properties and Photoreactivity. Organometallics 2017, 36, 2654-2660; (c) Sawahata, H.; Maruyama, M.; Cuong Nguyen, T.; Omachi, H.; Shinohara, H.; Okada, S., Band-Gap Engineering of Graphene Heterostructures by Substitutional Doping with $\mathrm{B}_{3} \mathrm{~N}_{3}$. ChemPhysChem 2017, 19, 237-242; (d) Baggett, A. W.; Guo, F.; Li, B.; Liu, S.-Y.; Jäkle, F., Regioregular Synthesis of Azaborine Oligomers and a Polymer with a syn Conformation Stabilized by N-H $\cdots \pi$ Interactions. Angew. Chem. Int. Ed. 2015, 54, 11191-11195; (e) van de Wouw, H. L.; Lee, J. Y.; Awuyah, E. C.; Klausen, R. S., A BN Aromatic Ring Strategy for Tunable Hydroxy Content in Polystyrene. Angew. Chem. Int. Ed. 2018, 57, 1673-1677; (f) Wan, W.-M.; Baggett, A. W.; Cheng, F.; Lin, H.; Liu, S.-Y.; Jäkle, F., Synthesis by free radical polymerization and properties of $\mathrm{BN}-$ polystyrene and $\mathrm{BN}-$ poly(vinylbiphenyl). Chem. Commun. 2016, 52, 13616-13619.

14. (a) Dou, C.; Ding, Z.; Zhang, Z.; Xie, Z.; Liu, J.; Wang, L., Developing Conjugated Polymers with High Electron Affinity by Replacing a C-C Unit with a BヶN Unit. Angew. Chem. Int. Ed. 2015, 54, 3648-3652; (b) Lorenz, T.; Lik, A.; Plamper, F. A.; Helten, H., Dehydrocoupling and Silazane Cleavage Routes to Organic-Inorganic Hybrid Polymers with NBN Units in the Main Chain. Angew. Chem. Int. Ed. 2016, 55, 7236-7241; (c) Lorenz, T.; Crumbach, M.; Eckert, T.; Lik, A.; Helten, H., Poly(p-phenylene iminoborane): A Boron-Nitrogen Analogue of Poly(p-phenylene vinylene). Angew. Chem. Int. Ed. 2017, 56, 2780-2784; (d) Wang, X.-Y.; Zhuang, F.-D.; Wang, J.-Y.; Pei, J., Incorporation of polycyclic azaborine compounds into polythiophene-type conjugated polymers for organic field-effect transistors. Chem. Commun. 2015, 51, 17532-17535; (e) Ayhan, O.; Eckert, T.; Plamper, F. A.; Helten, H., Poly(iminoborane)s: An Elusive Class of Main-Group Polymers? Angew. Chem. Int. Ed. 2016, 55, 13321-13325; (f) Ayhan, O.; Riensch, N. A.; Glasmacher, C.; Helten, H., Cyclolinear Oligo- and Poly(iminoborane)s: The Missing Link in Inorganic Main-Group Macromolecular Chemistry. Chem. Eur. J. 2018, 24, 5883-5894.

15. (a) Moliton, A.; Hiorns, R. C., Review of electronic and optical properties of semiconducting $\pi$-conjugated polymers: applications in optoelectronics. Polym. Int. 2004, 53, 1397-1412; (b) Heeger, A. J., Semiconducting polymers: the Third Generation. Chem. Soc. Rev. 2010, 39, 2354-2371; (c) Facchetti, A., $\pi$-Conjugated Polymers for Organic Electronics and Photovoltaic Cell Applications. Chem. Mater. 2011, 23, 733-758; (d) Dou, L.; You, J.; Hong, Z.; Xu, Z.; Li, G.; Street, R. A.; Yang, Y., 25 th Anniversary Article: A Decade of Organic/Polymeric Photovoltaic Research. Adv. Mater. 2013, 25, 6642-6671; (e) Shirakawa, H.; Louis, E. J.; MacDiarmid, A. G.; Chiang, C. K.; Heeger, A. J., Synthesis of electrically conducting organic polymers: halogen derivatives of polyacetylene, (CH). J. Chem. Soc., Chem. Commun. 1977, 578-580.

16. (a) Facchetti, A., П-conjugated polymers for organic electronics and photovoltaic cell applications. Chem. Mater. 2010, 23, 733-758; (b) Zhang, Z.; Liao, M.; Lou, H.; Hu, Y.; Sun, X.; Peng, H., Conjugated Polymers for Flexible Energy Harvesting and Storage. Adv. Mater. 2018, 30, 1704261; (c) Swager, T. M., 50th Anniversary Perspective: Conducting/Semiconducting Conjugated Polymers. A Personal Perspective on the Past and the Future. Macromolecules 2017, 50, 4867-4886; (d) Wang, C.; Dong, H.; Hu, W.; Liu, Y.; Zhu, D., Semiconducting $\pi$-conjugated systems in field-effect transistors: a material odyssey of organic electronics. Chem. Rev. 2011, 112, 2208-2267. 
17. (a) Takimiya, K.; Osaka, I.; Nakano, M., $\pi$-Building Blocks for Organic Electronics: Revaluation of "Inductive" and "Resonance" Effects of $\pi$-Electron Deficient Units. Chem. Mater. 2014, 26, 587-593; (b) Li, G.; Chang, W.-H.; Yang, Y., Low-bandgap conjugated polymers enabling solution-processable tandem solar cells. Nature Rev. Mater. 2017, 2, 17043.

18. (a) Edel, K.; Brough, S. A.; Lamm, A. N.; Liu, S.-Y.; Bettinger, H. F., 1,2-Azaborine: The Boron-Nitrogen Derivative of ortho-Benzyne. Angew. Chem. Int. Ed. Engl. 2015, 54, 7819-7822; (b) Noda, H.; Furutachi, M.; Asada, Y.; Shibasaki, M.; Kumagai, N., Unique physicochemical and catalytic properties dictated by the $\mathrm{B}_{3} \mathrm{NO}_{2}$ ring system. Nat. Chem. 2017, 9, 571.

19. (a) Jäkle, F., Advances in the Synthesis of Organoborane Polymers for Optical, Electronic, and Sensory Applications. Chem. Rev. 2010, 110, 3985-4022; (b) Snyder, J. A.; Grüninger, P.; Bettinger, H. F.; Bragg, A. E., Excited-State Deactivation Pathways and the Photocyclization of BN-Doped Polyaromatics. J. Phys. Chem. A 2017, 121, 5136-5146; (c) Dou, C.; Long, X.; Ding, Z.; Xie, Z.; Liu, J.; Wang, L., An Electron-Deficient Building Block Based on the $\mathrm{B} \leftarrow \mathrm{N}$ Unit: An Electron Acceptor for All-Polymer Solar Cells. Angew. Chem. Int. Ed. 2016, 55, $1436-1440$.

20. (a) Chen, D.-M.; Qin, Q.; Sun, Z.-B.; Peng, Q.; Zhao, C.-H., Synthesis and properties of B,N-bridged p-terphenyls. Chem. Commun. 2014, 50, 782-784; (b) Müller, M.; Behnle, S.; Maichle-Mössmer, C.; Bettinger, H. F., Boron-nitrogen substituted perylene obtained through photocyclisation. Chem. Commun. 2014, 50, 7821-7823.

21. Wakamiya, A.; Ide, T.; Yamaguchi, S., Toward $\pi$-Conjugated Molecule Bundles: Synthesis of a Series of B,B',B"'-Trianthryl-N,N',N"-triarylborazines and the Bundle Effects on Their Properties. J. Am. Chem. Soc. 2005, 127, 14859-14866.

22. (a) Holliday, S.; Donaghey, J. E.; McCulloch, I., Advances in Charge Carrier Mobilities of Semiconducting Polymers Used in Organic Transistors. Chem. Mater. 2014, 26, 647-663; (b) Arias, A. C.; MacKenzie, J. D.; McCulloch, I.; Rivnay, J.; Salleo, A., Materials and Applications for Large Area Electronics: Solution-Based Approaches. Chem. Rev. 2010, 110, 3-24; (c) Bhatt, M. P.; Magurudeniya, H. D.; Rainbolt, E. A.; Huang, P.; Dissanayake, D. S.; Biewer, M. C.; Stefan, M. C., Poly(3-Hexylthiophene) Nanostructured Materials for Organic Electronics Applications. J. Nanosci. Nanotechnol. 2014, 14, 1033-1050.

23. (a) Kalashnyk, N.; Ganesh Nagaswaran, P.; Kervyn, S.; Riello, M.; Moreton, B.; Jones, T. S.; De Vita, A.; Bonifazi, D.; Costantini, G., Self-Assembly of Decoupled Borazines on Metal Surfaces: The Role of the Peripheral Groups. Chem. Eur. J. 2014, 20, 11856-11862; (b) Kervyn, S.; Kalashnyk, N.; Riello, M.; Moreton, B.; Tasseroul, J.; Wouters, J.; Jones, T. S.; De Vita, A.; Costantini, G.; Bonifazi, D., "Magic” Surface Clustering of Borazines Driven by Repulsive Intermolecular Forces. Angew. Chem. Int. Ed. 2013, 52, 7410-7414.

24. Groszos, S. J.; Stafiej, S. F., Organoboron Compounds. I. A New Synthesis of B-Trialkyl and Triaryl-N-triphenylborazoles1. J. Am. Chem. Soc. 1958, 80, 1357-1360.

25. Smith, B. C.; Thakur, L., Boron-Nitrogen Bond Strengths in Borazoles. Nature 1965, 208, 74-75.

26. (a) Vogtle, F.; Gorka, M.; Hesse, R.; Ceroni, P.; Maestri, M.; Balzani, V., Photochemical and photophysical properties of poly(propylene amine) dendrimers with peripheral naphthalene and azobenzene groups. Photochem. Photobiol. Sci. 2002, 1, 45-51; (b) Conti, I.; Garavelli, M.; Orlandi, G., The Different Photoisomerization Efficiency of Azobenzene in the Lowest $n \pi^{*}$ and $\pi \pi^{*}$ Singlets: The Role of a Phantom State. J. Am. Chem. Soc. 2008, 130, 5216-5230. 
27. Wei-Guang Diau, E., A New Trans-to-Cis Photoisomerization Mechanism of Azobenzene on the S1(n, $\left.\pi^{*}\right)$ Surface. J. Phys. Chem. A 2004, 108, 950-956.

28. Yoon, S.-J.; Chung, J. W.; Gierschner, J.; Kim, K. S.; Choi, M.-G.; Kim, D.; Park, S. Y., Multistimuli Two-Color Luminescence Switching via Different Slip-Stacking of Highly Fluorescent Molecular Sheets. J. Am. Chem. Soc. 2010, 132, 13675-13683.

29. (a) Spano, F. C.; Silva, C., H- and J-Aggregate Behavior in Polymeric Semiconductors. Annu. Rev. Phys. Chem. 2014, 65, 477-500; (b) Carminati, R.; Greffet, J. J.; Henkel, C.; Vigoureux, J. M., Radiative and non-radiative decay of a single molecule close to a metallic nanoparticle. Opt. Commun. 2006, 261, 368-375; (c) Chen, J.; Law, C. C. W.; Lam, J. W. Y.; Dong, Y.; Lo, S. M. F.; Williams, I. D.; Zhu, D.; Tang, B. Z., Synthesis, Light Emission, Nanoaggregation, and Restricted Intramolecular Rotation of 1,1-Substituted 2,3,4,5-Tetraphenylsiloles. Chem. Mater. 2003, 15, 1535-1546; (d) Hong, Y.; Lam, J. W. Y.; Tang, B. Z., Aggregation-induced emission. Chem. Soc. Rev. 2011, $40,5361-5388$.

30. (a) Hong, Y.; Lam, J. W. Y.; Tang, B. Z., Aggregation-induced emission: phenomenon, mechanism and applications. Chem. Commun. 2009, 4332-4353; (b) Xu, B.; He, J.; Dong, Y.; Chen, F.; Yu, W.; Tian, W., Aggregation emission properties and self-assembly of conjugated oligocarbazoles. Chem. Commun. 2011, 47, 6602-6604.

31. Han, M.; Cho, S. J.; Norikane, Y.; Shimizu, M.; Kimura, A.; Tamagawa, T.; Seki, T., Multistimuli-responsive azobenzene nanofibers with aggregation-induced emission enhancement characteristics. Chem. Commun. 2014, 50, $15815-15818$.

32. (a) Horn, D.; Rieger, J., Organic Nanoparticles in the Aqueous Phase-Theory, Experiment, and Use. Angew. Chem. Int. Ed. 2001, 40, 4330-4361; (b) Yin, Y.; Alivisatos, A. P., Colloidal nanocrystal synthesis and the organic-inorganic interface. Nature 2005, 437, 664-670.

33. Davey, M.; Lee, V.; Miller, R.; Marks, T. J., Synthesis of aryl nitroso derivatives by tert-butyl hypochlorite oxidation in homogeneous media. Intermediates for the preparation of high-hyperpolarizability chromophore skeletons. J. Org. Chem. 1999, 64, 4976-4979.

34. (a) Dias, F. B.; Pollock, S.; Hedley, G.; Pålsson, L.-O.; Monkman, A.; Perepichka, I. I.; Perepichka, I. F.; Tavasli, M.; Bryce, M. R., Intramolecular Charge Transfer Assisted by Conformational Changes in the Excited State of Fluorene-dibenzothiophene-S,S-dioxide Co-oligomers. J. Phys. Chem. B 2006, 110, 19329-19339; (b) Pop, F.; Riobé, F.; Seifert, S.; Cauchy, T.; Ding, J.; Dupont, N.; Hauser, A.; Koch, M.; Avarvari, N., Tetrathiafulvalene-1,3,5-triazines as (Multi)Donor-Acceptor Systems with Tunable Charge Transfer: Structural, Photophysical, and Theoretical Investigations. Inorg. Chem. 2013, 52, 5023-5034.

35. Lausi, A.; Polentarutti, M.; Onesti, S.; Plaisier, J. R.; Busetto, E.; Bais, G.; Barba, L.; Cassetta, A.; Campi, G.; Lamba, D.; Pifferi, A.; Mande, S. C.; Sarma, D. D.; Sharma, S. M.; Paolucci, G., Status of the crystallography beamlines at Elettra. Eur. Phys. J. Plus 2015, 130, 43.

36. Kabsch, W., XDS. Acta Crystallogr. Sect. D Biol. Crystallogr. 2010, 66, 125-132.

37. Burla, M. C.; Caliandro, R.; Carrozzini, B.; Cascarano, G. L.; Cuocci, C.; Giacovazzo, C.; Mallamo, M.; Mazzone, A.; Polidori, G., Crystal structure determination and refinement via SIR2014. J. Appl. Crystallogr. 2015, 48, 306-309.

38. Sheldrick, G., Crystal structure refinement with SHELXL. Acta Crystallogr. Sect. C 2015, 71, 3-8. 
39. Emsley, P.; Lohkamp, B.; Scott, W. G.; Cowtan, K., Features and development of Coot. Acta Crystallogr. Sect. D 2010, 66, 486-501.

40. Nguyen, H. T.; Coulembier, O.; Gheysen, K.; Martins, J. C.; Dubois, P., Copper-Catalyzed Dehydrogenative Polycondensation of a Bis-Aniline Hexylthiophene-Based Monomer: A Kinetically Controlled Air-Tolerant Process. Macromolecules 2012, 45, 9547-9550. 